\title{
Synthesis and application of luminescent single CdS quantum dot encapsulated silica nanoparticles directed for precision optical bioimaging
}

This article was published in the following Dove Press journal:

International Journal of Nanomedicine

16 July 2012

Number of times this article has been viewed

Srivani Veeranarayanan

Aby Cheruvathoor Poulose

M Sheikh Mohamed

Yutaka Nagaoka

Seiki Iwai

Yuya Nakagame

Shosaku Kashiwada

Yasuhiko Yoshida

Toru Maekawa

D Sakthi Kumar

Bio Nano Electronics Research Centre, Graduate School of Interdisciplinary New Science,

Toyo University, Kawagoe, Japan
Correspondence: D Sakthi Kumar 2100 , Kujirai, Kawagoe, Saitama, 350-8585, Japan

$\mathrm{Tel}+8149239 \quad 1636$

Fax +8I 492342502

Email sakthi@toyo.jp
Abstract: This paper presents the synthesis of aqueous cadmium sulfide (CdS) quantum dots (QDs) and silica-encapsulated CdS QDs by reverse microemulsion method and utilized as targeted bio-optical probes. We report the role of $\mathrm{CdS}$ as an efficient cell tag with fluorescence on par with previously documented cadmium telluride and cadmium selenide QDs, which have been considered to impart high levels of toxicity. In this study, the toxicity of bare QDs was efficiently quenched by encapsulating them in a biocompatible coat of silica. The toxicity profile and uptake of bare CdS QDs and silica-coated QDs, along with the CD31-labeled, silica-coated CdS QDs on human umbilical vein endothelial cells and glioma cells, were investigated. The effect of size, along with the time-dependent cellular uptake of the nanomaterials, has also been emphasized. Enhanced, high-specificity imaging toward endothelial cell lines in comparison with glioma cells was achieved with CD31 antibody-conjugated nanoparticles. The silica-coated nanomaterials exhibited excellent biocompatibility and greater photostability inside live cells, in addition to possessing an extended shelf life. In vivo biocompatibility and localization study of silica-coated CdS QDs in medaka fish embryos, following direct nanoparticle exposure for 24 hours, authenticated the nanomaterials' high potential for in vivo imaging, augmented with superior biocompatibility. As expected, CdS QD-treated embryos showed 100\% mortality, whereas the silica-coated QD-treated embryos stayed viable and healthy throughout and after the experiments, devoid of any deformities. We provide highly cogent and convincing evidence for such silica-coated QDs as a model nanoparticle in practice, to achieve in vitro and in vivo precision targeted imaging.

Keywords: endothelial imaging, CD31, silica nanoparticle, CdS QDs, medaka embryos, biocompatibility

\section{Introduction}

Colloidal nanomaterials have attracted immense attention in both fundamental studies and technical applications. The exponential increase in the use of nanomaterials in various fields testifies to their impact. ${ }^{1,2}$ Quantum dots (QDs) are inorganic fluorophores that demonstrate potential in numerous applications. Due to their unique, size-dependent optical and electronic properties, these materials are widely used for biological imaging and in electronic industries. ${ }^{3-6}$ These materials are highly photostable and are considered promising alternatives when compared with their organic counterparts in similar application fields. ${ }^{7}$ QDs present many advantages, such as size-tunable emissions, broad absorption, and narrow emission spectra. However, there are certain disadvantages that limit their use in biological imaging. ${ }^{8-10}$ Most QDs are cadmium based and are highly detrimental to cells due to the release of $\mathrm{Cd}^{2+}$ ions. ${ }^{11-16}$ The cytotoxicity and ecotoxicity of 
these materials need to be minimized to be considered as feasible cell tags for biological imaging. These QDs are synthesized via organometallic routes under high temperatures, rigorous conditions, and in inert atmospheres, ${ }^{17,18}$ demanding highly sophisticated setups and posing imminent complications. Therefore, it remains a challenge to find an appropriate, straightforward, and efficient method for QD synthesis. Another imposing limitation is that synthesized QDs are not water-soluble. ${ }^{19}$ The most commonly used passivators to make these QDs water-soluble are toxic. ${ }^{20,21}$ Thus, imparting toxic linker-assisted water solubility does not address the real issue of QD toxicity. To render QDs water-soluble, two main approaches are currently used. The first method uses organic polymers or thiol groups as linker molecules, ${ }^{22-26}$ whereas the second method applies well-studied silica chemistry. ${ }^{27-30}$ Silica-coating of QDs is widely appreciated and accepted as an efficient means to undermine the toxicity of QDs and to impart biocompatibility. Mesoporous silica materials are considered appropriate candidates for the surface passivation of QDs. The silica-coating technique is used as a nanoplatform to make other novel hybrid nanoparticle architectures for in vitro and in vivo optical imaging applications. ${ }^{31-33}$ Surface coating with silica shells yields less toxicity and high photostability, in addition to minimizing oxidation of the QD core. In addition, silica is an inert layer that confers water solubility and shields the optical property of the core. ${ }^{34-38}$ Cadmium selenide and cadmium telluride QDs have been widely synthesized and studied as cyto-labels. ${ }^{39-41}$ Cadmium sulfide (CdS) QDs have, as of yet, not created their own niche in the area of biological imaging due to their weak emissions in comparison with their selenide and telluride counterparts. Furthermore, reports narrating CdS QDs as efficient cell tags are extremely inadequate. ${ }^{42,43}$

Research in the area of targeted endothelial labeling employing CD31 antibodies is extremely limited. CD31 is predominantly expressed in endothelial cells and is not a feature of cell lines from any other origin. Endothelial cells line the lumen of blood vessels and represent a vital therapeutic site for treating a plethora of diseases, ranging from neurological ailments to cancer. The targeting of drugs and imaging agents to endothelial cells can be challenging, in part because the flow transports blood components - including drug carriers - at the speed of roughly 10 endothelial cell lengths per second in the capillaries. After intravenous injection, for example, drugs and drug carriers conjugated with antibodies to the endothelial surface molecule CD31 bind to the endothelium. ${ }^{40}$ Endothelial immunotargeting augments the effectiveness of and specificity related to the therapeutic feat of diverse drugs in animal models of thrombosis, ischemia, lysosomal storage diseases, and inflammation. Thus, endothelial drug delivery (vascular immunotargeting) represents a translational goal of broad importance.

Here, we report the synthesis of CdS QDs via the reverse microemulsion method. QDs synthesized this way are watersoluble and ready to use. To counter the issue of $\mathrm{Cd}^{2+}$ ions leaching and posing toxicity to biological entities, QDs were encapsulated in a silica shell. These silica-CdS QDs were then utilized efficiently for cell labeling. We imaged two different cell lines: normal human umbilical vein endothelial cells (HUVECs) and the brain cancer cell line, glioma (Gl-1). The time-dependent uptake of bare and silica-coated QDs by these cell lines has been documented. In vivo imaging has been conducted using medaka fish embryos, to understand the biocompatibility and imaging capability of bare and silica-coated QDs inside a living organism. To attain high specificity, the silica-coated QDs were labeled with the CD31 antibody, an endothelial marker highly specific to vascular lineage cells. Although silica-coated cadmium selenide and cadmium telluride QDs have been previously documented and used for labeling cells, ${ }^{31-33}$ the fabrication of silicacoated CdS QDs and their in vitro and in vivo bioimaging applications have been unreported and remain elusive to date. We propose the present synthesis methodology as an easy, economic method that does not need rigorous conditions or have complex requirements. QDs are synthesized rapidly (within 5 minutes) and are highly luminescent.

\section{Materials and methods Materials}

Cadmium nitrate, ammonium sulfide, cyclohexane, IGEPAL $^{\circledR}$, deionized water, tetraethoxysilane, ammonia, acetone, $2^{\prime}, 7^{\prime}$-dichlorfluorescein-diacetate, and a Coomassie protein estimation kit were all purchased from Sigma-Aldrich (St Louis, MO). All chemicals were of an analytical grade. Mouse monoclonal CD31 antibody was purchased from Invitrogen (Carlsbad, CA). HUVECs were purchased from Gibco (Carlsbad, CA) and Gl-1 cells from Riken BioResource (Tsukuba-shi, Japan). Medium 200, Dulbecco's modified Eagle's medium (DMEM), heat-inactivated newborn calf serum, phosphate-buffered saline (PBS), trypsinase, and alamarBlue $^{\circledR}$ were acquired from Invitrogen.

\section{Preparation of bare CdS and silica-coated CdS}

First, CdS QDs were prepared via a reverse microemulsion method. Subsequently, reverse water-in-oil microemulsions 
were prepared using cyclohexane and IGEPAL. A total of $20 \mathrm{~mL}$ of cyclohexane was mixed with $8 \mathrm{~mL}$ of IGEPAL to form a microemulsion. An aqueous solution of cadmium nitrate (190 $\mathrm{mg}$ in $2 \mathrm{~mL}$ deionized water) was added to the first microemulsion and $2 \mathrm{~mL}$ of an ammonium sulfide solution $(0.01 \mathrm{M})$ were added to the second and continuously stirred. The two microemulsions were mixed together after 5 minutes and the development of a yellow color was noted, indicating the formation of CdS QDs. The so-synthesized QDs were precipitated and repeatedly washed with $25 \mathrm{~mL}$ of ethanol, then centrifuged to obtain the QDs. For silica-coated QDs, $1 \mathrm{~mL}$ of tetraethoxysilane and $0.2 \mathrm{~mL}$ of a $28 \%$ ammonia solution were added to the $\mathrm{CdS}$ solution. The stirring continued for 8 hours, then precipitated with acetone, repeatedly washed with $25 \mathrm{~mL}$ of ethanol, and then thrice with $25 \mathrm{~mL}$ of double-distilled $\mathrm{H}_{2} \mathrm{O}$. The final product was desiccated to obtain water-soluble, silica-coated CdS QDs.

\section{CD3 I antibody labeling of nanoparticles}

The silica-coated QDs were amine functionalized to facilitate the direct conjugation of CD31 antibodies onto the nanoparticle surface. Then the amine-functionalized nanoparticles $(10 \mathrm{mg})$ were stirred with $5 \%$ glutaraldehyde $(2 \mathrm{~mL})$ for 5 hours, then centrifuged and washed thrice with $10 \mathrm{~mL}$ of PBS. The resulting glutaraldehyde-conjugated nanoparticles were re-dispersed in PBS. CD31 antibodies $(50 \mu \mathrm{L})$ were added to this nanoparticle suspension and conjugation was carried out at $4^{\circ} \mathrm{C}$ under gentle shaking for 4 hours. The product was stored at $4^{\circ} \mathrm{C}$ until use. Figure 1 depicts the scheme for conjugating the CD31 antibodies to the amine-functionalized silica nanoparticles.

\section{Cell culture}

HUVECs were maintained in T25 flasks using Medium 200 supplemented with low serum growth supplements and antibiotics $(100 \mu / \mathrm{mL}$ penicillin and streptomycin). The cells were sub-cultured every 2 days. Gl-1 cells were maintained using DMEM supplemented with fetal bovine serum and antibiotics. The cells were sub-cultured every 4 days. Both cell lines were maintained in glass-base dishes and 96-well plates for confocal and cytotoxicity analysis, respectively. For cytotoxicity, reactive oxygen species (ROS) and Coomassie

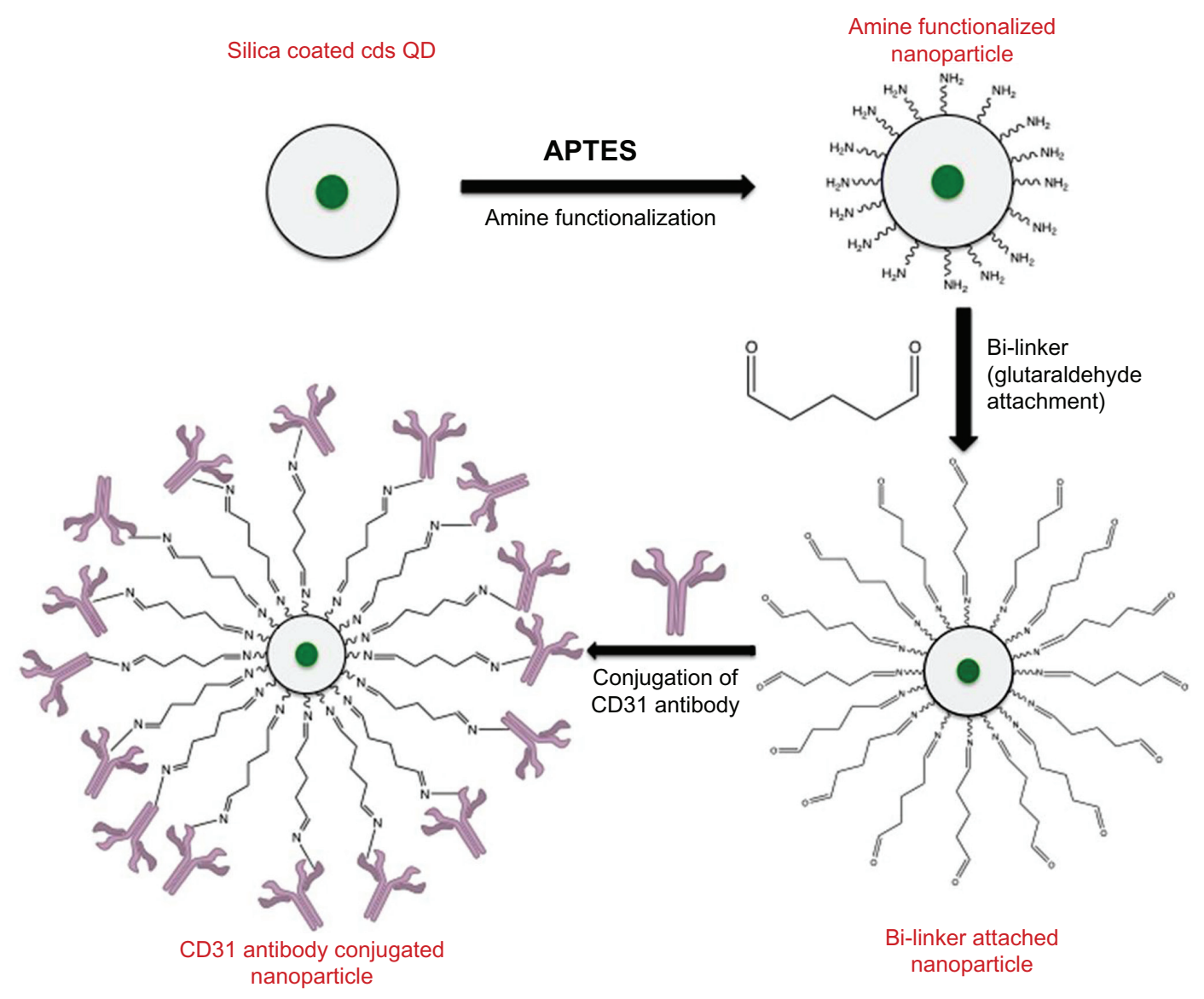

Figure I Schematic representation of CD3 I antibody conjugation onto silica coated CdS QDs. Abbreviations: APTES, 3-Aminopropyltriethoxysilane; CdS QD, cadmium sulfide quantum dot. 
cellular protein estimation assays, approximately 5000 cells were seeded into each of the 96-well plates. The cells were grown until visual confluency, then $100 \mu \mathrm{L}$ of CdS QDs, silica-coated CdS QDs, and targeted silica QDs were added at varied concentrations ( $1 \mathrm{mg}$ and 100,10 , and $1 \mu \mathrm{g}$ ). The control group was devoid of nanomaterials and the experiments were conducted in triplicate. After 24 hours of incubation with nanoparticles, the cells were washed with PBS and $0.2 \mathrm{~mL}$ of the respective medium was added. Cell viability was assayed with alamarBlue according to the manufacturer's instructions and the fluorescence at $570 \mathrm{~nm}$ was measured. The ROS, employing $2^{\prime}, 7^{\prime}$-dichlorfluorescein-diacetate dye, was measured at $480 \mathrm{~nm}$. The Coomassie protein reagent was employed for protein estimation studies and the resultant absorbance was read at $570 \mathrm{~nm}$.

Confocal microscopy was carried out to analyze the fluorescence of the nanomaterials. The cells were plated onto glass-base dishes and cultured until they attained $80 \%$ confluency. Subsequently, the nanomaterials were added to the plates at a concentration of $500 \mu \mathrm{g} / \mathrm{mL}$, and the cells were incubated for 2 hours at $37^{\circ} \mathrm{C}$ in an incubator maintained at $5 \% \mathrm{CO}_{2}$. The $500 \mu \mathrm{g} / \mathrm{mL}$ amount was chosen primarily because, at this concentration, the cells showed maximum viability with saturated fluorescence intensity. The cells were then washed with PBS and viewed under a confocal microscope at $488 \mathrm{~nm}$ excitation with a green filter. A time-dependent uptake study was carried out to visualize the effective imaging potential of the bare and coated QDs.

\section{In vivo biocompatibility and imaging of bare CdS and silica-coated CdS QDs}

Biocompatibility analysis and in vivo optical imaging of the medaka fish embryos were carried out by direct mediabased exposure. The medaka embryos were collected, sorted, and incubated with bare $\mathrm{CdS}$ and silica-coated $\mathrm{CdS}$ QDs at a concentration of $100 \mu \mathrm{g} / \mathrm{mL}$ of embryo-rearing medium (ERM). ${ }^{44}$ Fifteen embryos were chosen for treatment with each set of nanoparticles (control, CdS QDs, and silica-coated CdS QDs) and the experiment was carried out in duplicate. The treated embryos were incubated at $26^{\circ} \mathrm{C}$ for 1 day on a 16-/8-hour light-dark cycle. The embryos were rinsed on alternate days with ERM and analyzed for viability and morphological deformities. In addition, they were also viewed under a fluorescence microscope to assess their nanoparticle uptake. Nanoparticle exposure continued until Day 13, and the hatched fry were also visually analyzed.

\section{Instruments and measurements}

Particle morphology was studied with a field emission transmission electron microscope (TEM, JEM-2200-FS; JEOL, Tokyo, Japan). The synthesized particles were analyzed via TEM to obtain the fine structures of the CdS and silica-coated CdS QDs. The ultraviolet (UV)-visible and photoluminescence spectra of bare and silica-coated QDs were studied. The particles were dissolved in double-distilled $\mathrm{H}_{2} \mathrm{O}$, and the UV spectroscopy was carried out using a Shimadzu UV-2100PC/3100PC UV visible spectrometer (Kyoto, Japan). Photoluminescence spectra were recorded with an excitation wavelength of $360 \mathrm{~nm}$ using a JASCO FP-750 spectrophotometer (Tokyo, Japan). The quantum yield measurement was carried out using a Hitachi FP4500 spectrophotometer (Tokyo, Japan). Rhodamine 6G from Sigma-Aldrich (St Louis, MO) was used as the standard dye for quantum yield measurements. The particle suspension was illuminated using UV and its fluorescence captured via a Pentax Optio W80 digital camera (Pentax Ricoh Imaging Co, Tokyo, Japan). Energy-dispersive X-ray spectroscopy (EDS) and EDS mapping (JEOL JED-2300T) and X-ray photoelectron spectroscopy (XPS; Kratos Analytical, Tokyo, Japan) were carried out to analyze the elemental composition of bare, silica-coated, and targeted silica-coated QDs. Powder X-ray diffraction (XRD) pattern was carried out on a Rigaku (RINT) diffractometer (Tokyo, Japan) equipped with a rotating anode. The $2 \theta$ angle for the XRD spectra was recorded at a scanning rate of $5 \%$ minute.

Cytotoxicity studies were carried out using a microplate reader (Multidetection Microplate Scanner; Dainippon Sumitomo Pharma Co, Ltd, Osaka, Japan). The fluorescence of the nanomaterials inside live cells was visualized with the help of a confocal microscope (Olympus IX 81, under DU897 mode; Tokyo, Japan) using a fluorescein isothiocyanate filter. The viability of cells after treatment with nanomaterials was visualized with a phase contrast microscope (Nikon Eclipse TE2000-U; Nikon Instruments, Tokyo, Japan). A Leica Microsystems AF 600 fluorescence microscope (Wetzlar, Germany) was used for in vivo imaging and biocompatibility analysis of the medaka embryos under a GFP6 filter.

\section{Results and discussion}

\section{Structural and elemental characterization of bare and silica-coated CdS QDs}

To prepare CdS and silica-coated QDs, we utilized reverse microemulsion methodology as described. The nanoparticles (bare and silica-coated $\mathrm{CdS}$ ) were successfully synthesized and were highly water-soluble. This facilitated 
their use in in vitro studies without the need of any further surface modifications. As shown in the TEM micrograph, the CdS QDs (Figure 2A and B) were highly monodispersed and exhibited good crystal lattice fringes, with average sizes of 4-5 nm. Figure 2C and D show the TEM image of silicacoated CdS QDs. The silica-coated QDs were also highly monodispersed and each particle consisted of a single CdS QD at its core. The sizes of the silica-coated QDs were approximately 35-40 nm. The high-resolution TEM images of the silica-coated QDs are shown in Figure 2E and F. The crystal lattice patterns of CdS QDs encapsulated in silica shells were clearly visible. Nearly $90 \%$ of the particles were of uniform
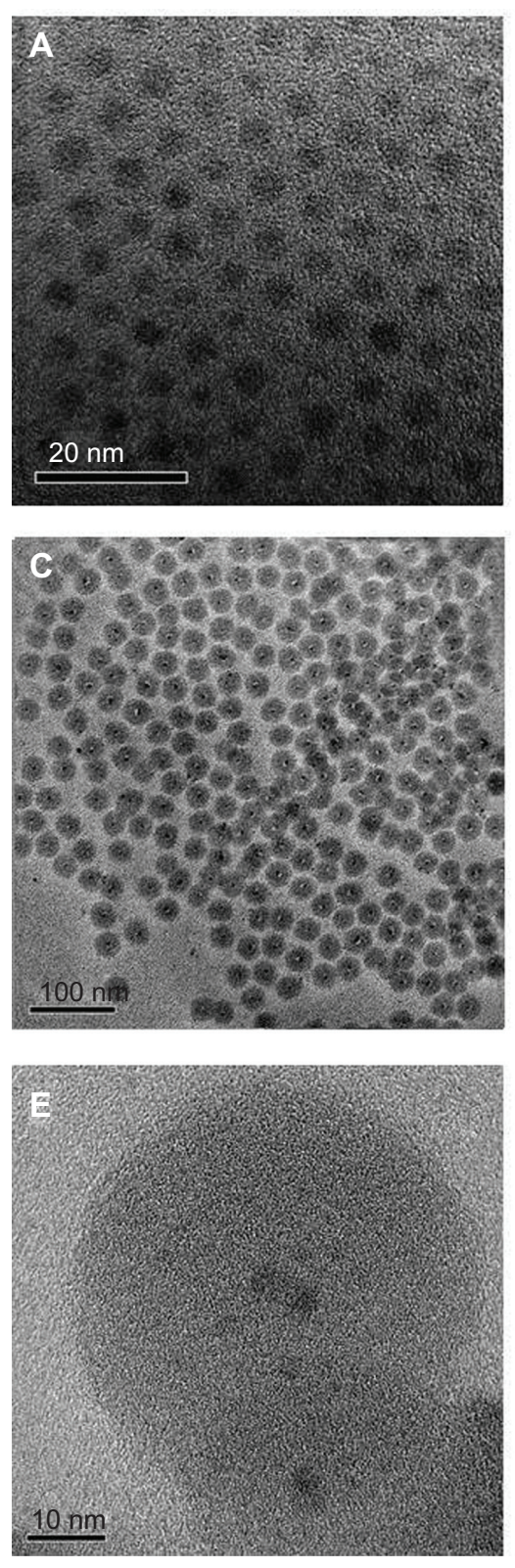

size (35-40 nm) and uniform spherical shape when the reaction time was 8 hours. In the case of targeted silica-coated QDs, no morphological differences with non-targeted nanomaterial were observed under TEM. We could also control the size of the silica coating when the reaction time was reduced from 8 hours. A thin silica coating was observed at 2-3 hours of reaction time. These thinly silica-coated CdS QDs rendered toxicity to cells, which may be attributed to cadmium ions leaching through the thin coat (data not shown).

Figure 3 shows the EDS spectra of bare (Figure 3A) and silica-coated QDs (Figure 3B). The presence of $\mathrm{Cd}$ and $\mathrm{S}$ confirmed the formation of CdS QDs, and the presence of
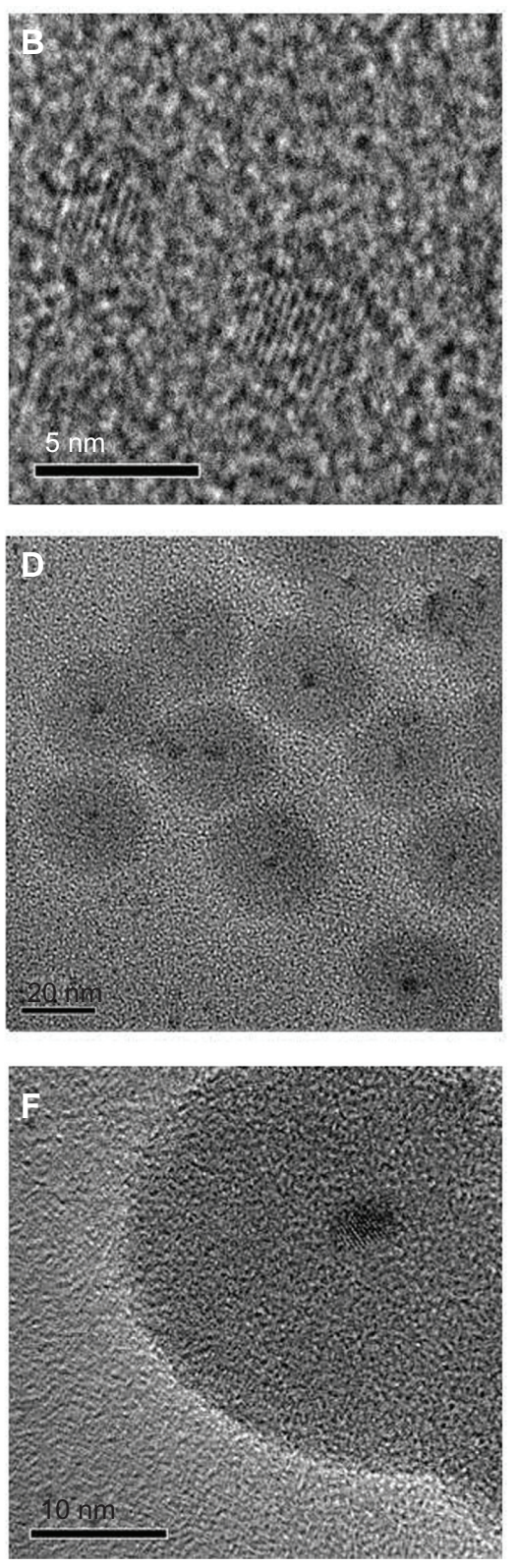

Figure 2 Transmission electron microscopy (TEM) images of bare cadmium sulfide quantum dots (CdS QDs; $\mathbf{A}$ and $\mathbf{B})$, silica-coated CdS QDs (C and D), and high-resolution TEM images of silica-coated CdS QDs (E and F). 


\section{A}

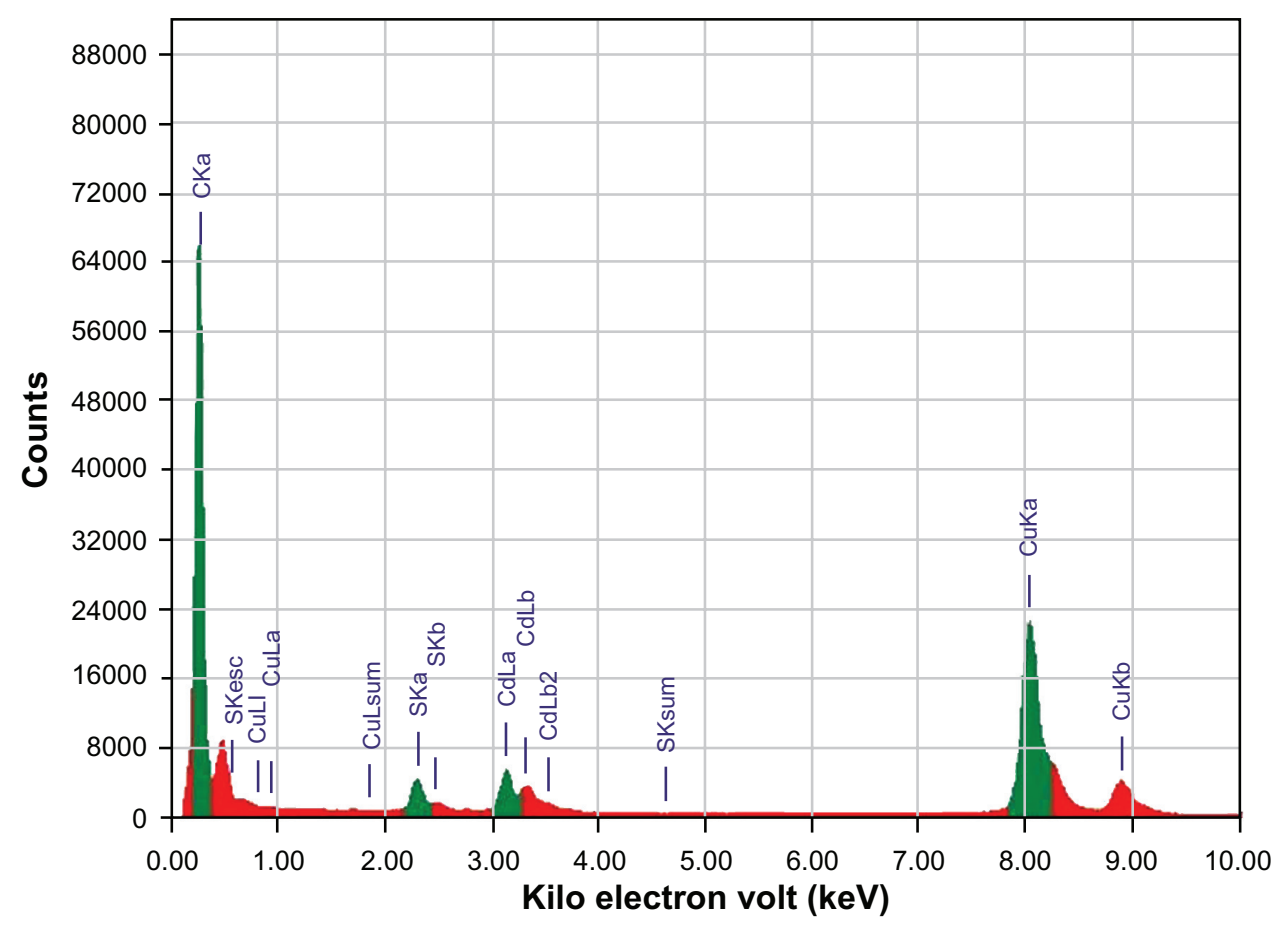

B

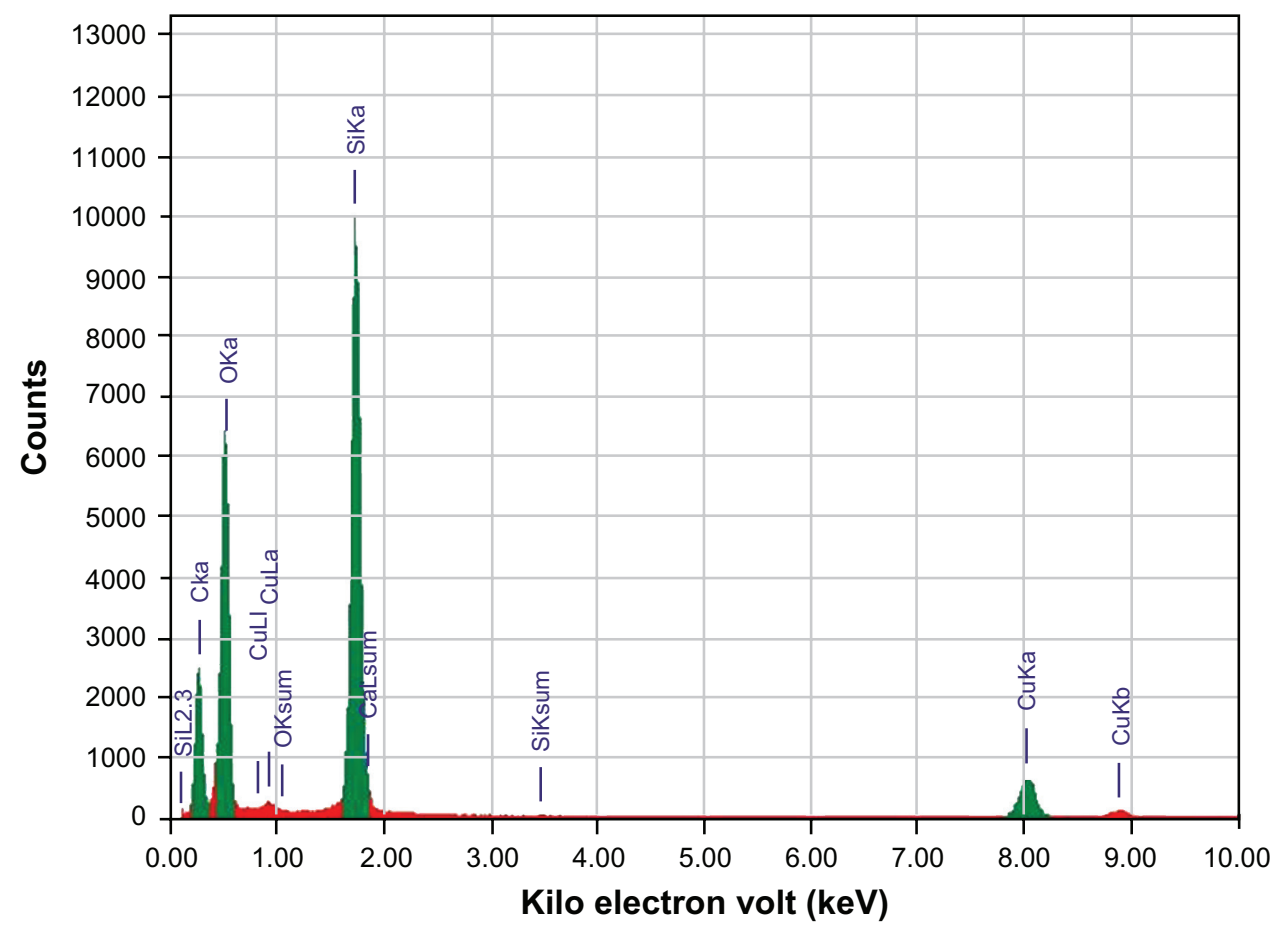

Figure 3 Energy-dispersive X-ray spectroscopy analysis of (A) bare cadmium sulfide quantum dots (CdS QDs) and (B) silica-coated CdS QDs.

only $\mathrm{Si}$ and $\mathrm{O}$ was noted in the case of silica-coated QDs. Figure 4 shows the XPS analysis of bare CdS QDs. Figure 4A and $\mathrm{B}$, correspond to the $\mathrm{Cd}$ and $\mathrm{S}$ peaks, whereas Figure $4 \mathrm{C}$ shows the wide XPS spectra of the CdS QDs. The presence of $\mathrm{Si}$ and $\mathrm{O}$ was from the silica substrate used while per- forming XPS. Figure 5 corresponds to the XPS analysis of silica-coated and CD31 antibody-targeted silica-coated QDs. The presence of $\mathrm{Si}$ and $\mathrm{O}$ was clear; the substrate used in this case was carbon tape. When CD31-conjugated silica-coated QDs were analyzed for elemental incidence, we observed an 
A

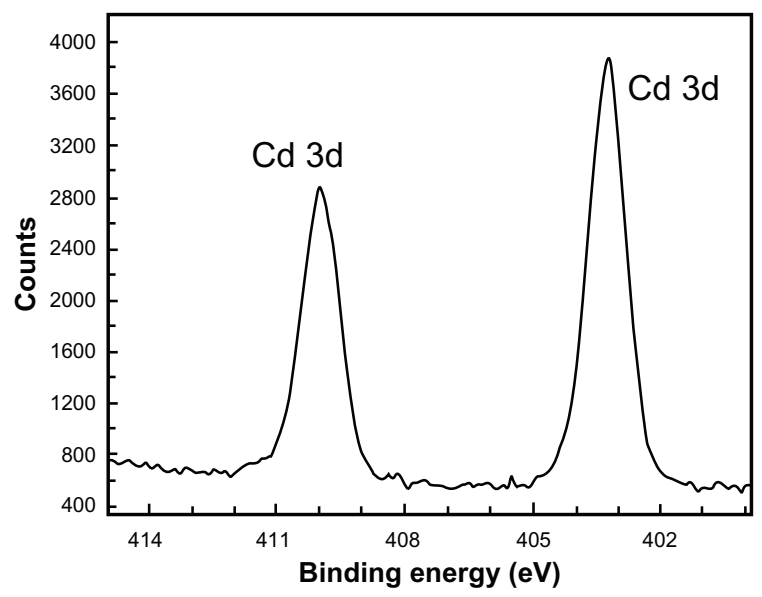

C

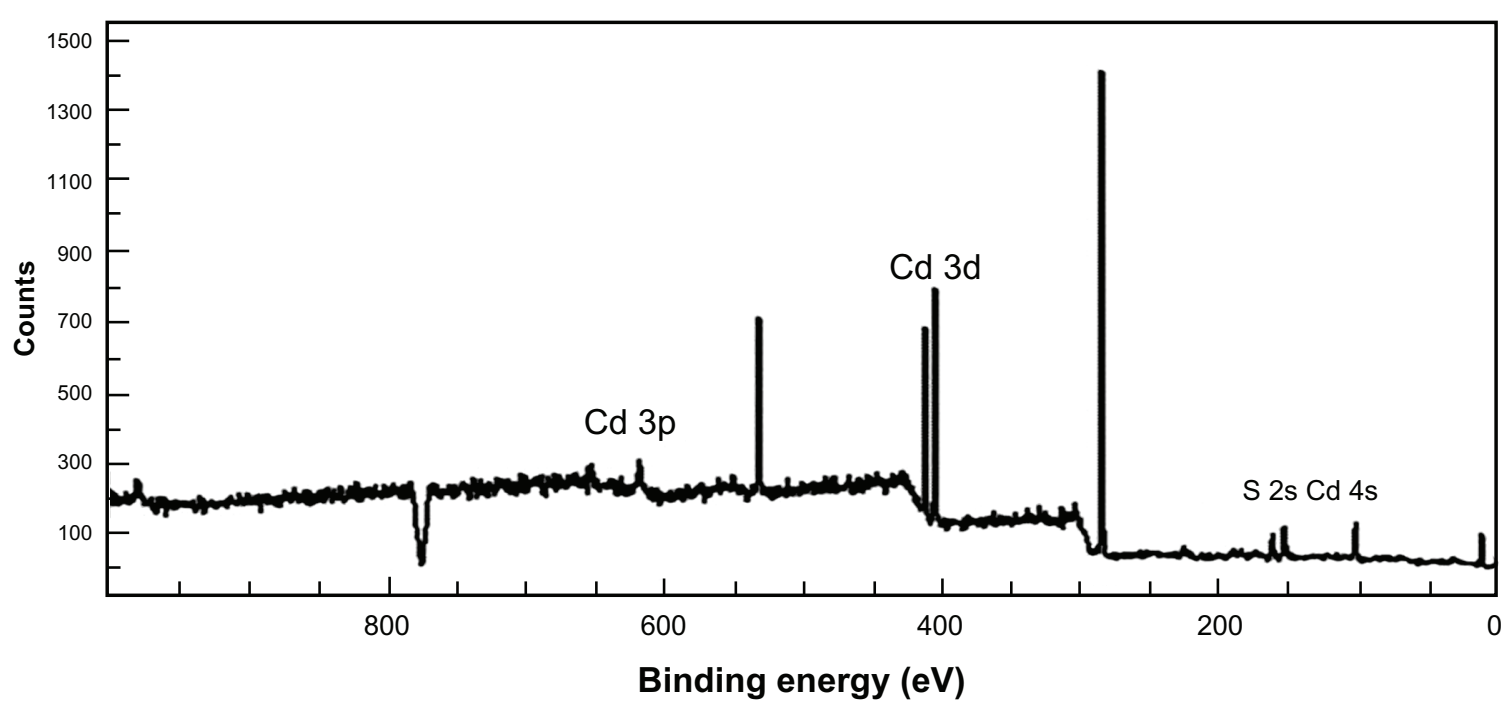

B

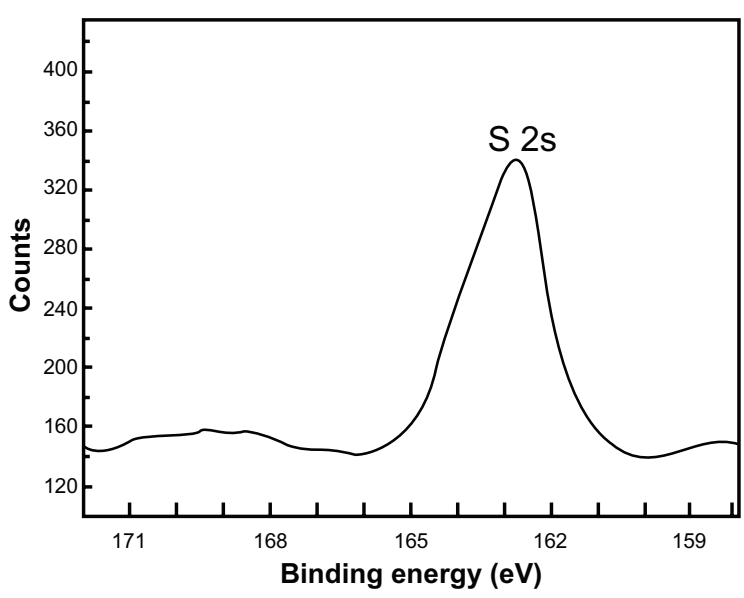

Figure 4 X-ray photoelectron spectroscopy analysis of cadmium (Cd) sulfide (S) QDs showing Cd (A) and S peaks (B) and of wide (C), respectively.

enhanced peak of $\mathrm{N}$ compared with the amine-functionalized counterpart, suggesting CD31 had successfully conjugated onto the silica-coated QDs (Figure 5 [bottom]). In both EDS and XPS, the presence of Cd and S peaks could not be observed in the case of silica-coated QDs. These particles, however, exhibited fluorescence under UV illumination. As bare Si particles are nonfluorescent, the fluorescence visualized is certainly from the CdS QDs encapsulated in the silica shell. TEM images also support the presence of CdS cores inside the silica shell. This clearly indicates that QDs were present deep inside the silica shell and were efficiently encapsulated, with no surface adherence of the QDs. EDS mapping was performed to analyze the presence of $\mathrm{CdS}$ deep inside the silica shell (Figure 6). Figure 6A shows the highresolution TEM image of the sample area where mapping was performed. B-E of Figure 6 correspond to the mapping of the elements $\mathrm{Cd}, \mathrm{S}, \mathrm{Si}$, and $\mathrm{O}$, respectively. The presence of 


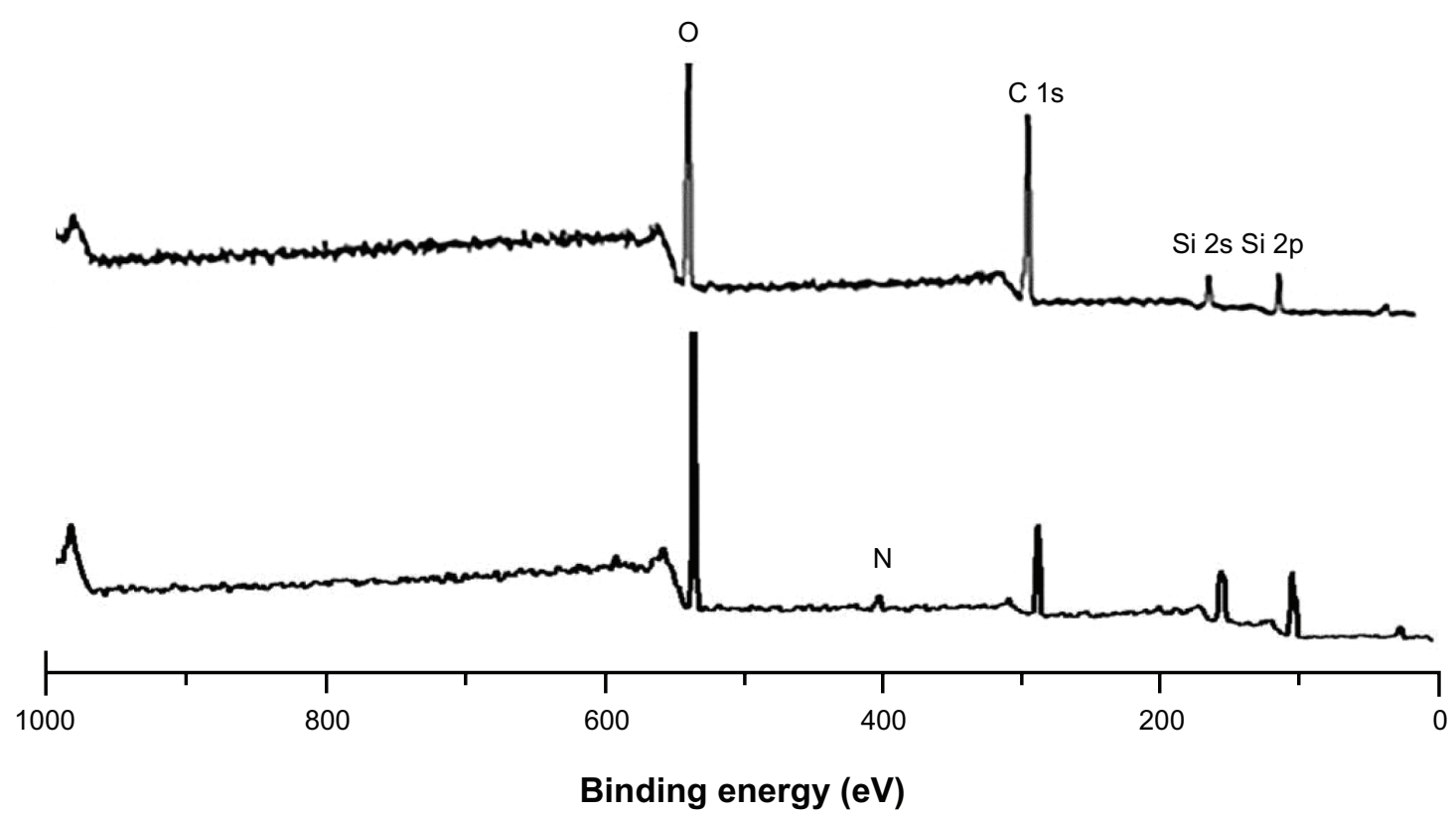

Figure 5 X-ray photoelectron spectroscopy analysis of silica-coated cadmium sulfide (CdS) quantum dots (top) and CD3I antibody-labeled silica-coated CdS QDs (bottom spectrum).

and a clear emission peak was noted, centered at $600 \mathrm{~nm}$ for both particles. Figure 7 (inset) shows UV illumination of bare and silica-coated CdS QDs. The quantum yields of bare and silica-coated CdS QDs were found to be $0.02 \%$ and $0.03 \%$, respectively. The conjugation of CD31 did not alter any of the optical characteristics of silica-coated $\mathrm{CdS}$ QDs. To assess and affirm the increased shelf-life stability of the silica-coated CdS QDs, UV luminescent images of the nanomaterials after 3 months of storage (Figure S2) were recorded. The silica-coated QDs exhibited excellent fluorescence under UV light, even after storage under normal light for such an extended period. In stark contrast, the fluorescence of QDs without a silica coating was observed to have diminished drastically under normal light and no fluorescence was recorded after 1 month. This clearly favors our claim regarding the long-term storage capability

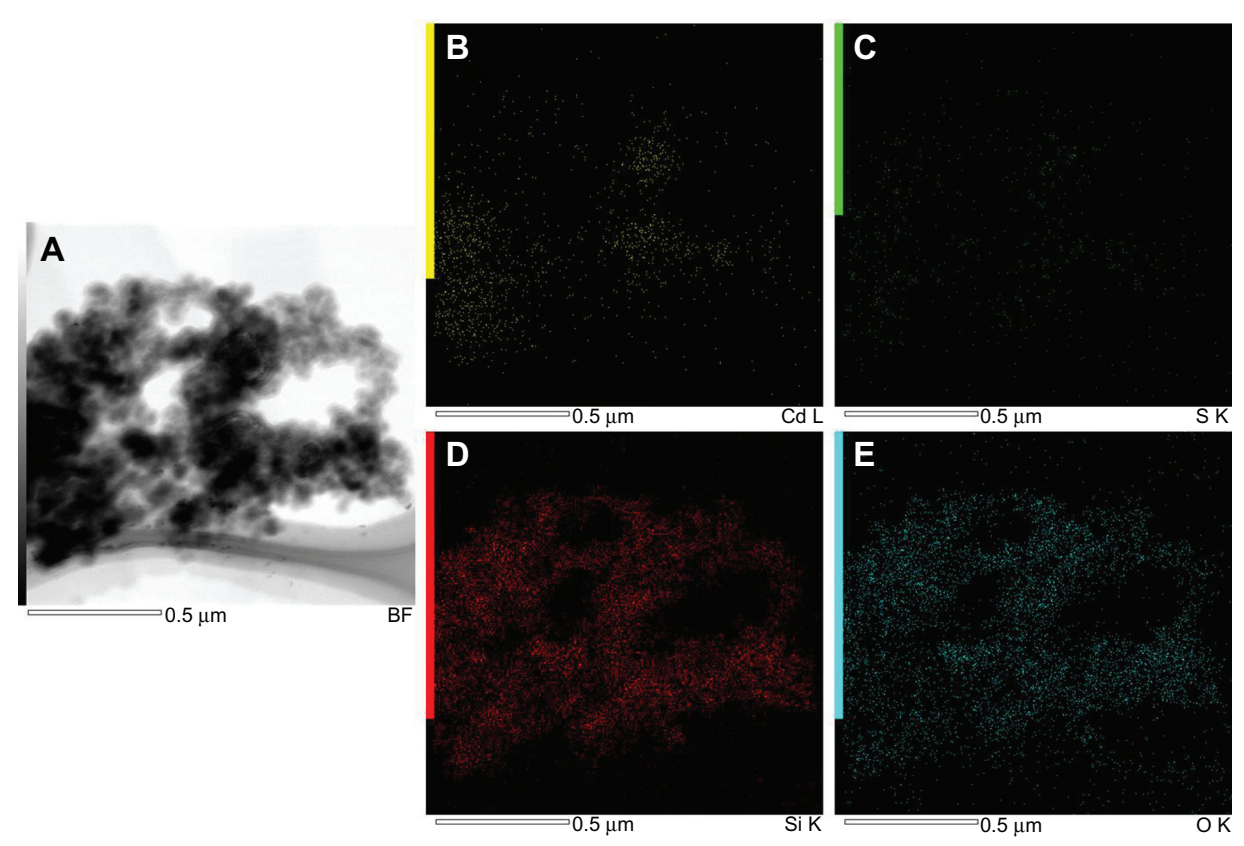

Figure 6 Energy-dispersive X-ray spectroscopy mapping of cadmium sulfide quantum dots coated with silica. (A) Transmission electron microscopy image. (B) Cadmium mapping. (C) Sulfur mapping. (D) Silicon mapping. (E) Oxygen mapping. 


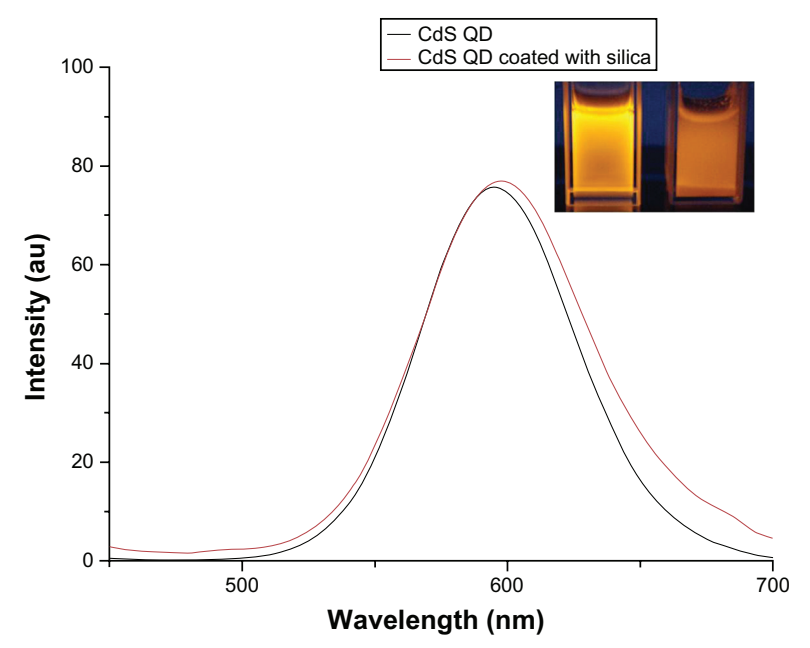

Figure 7 Photo luminescence spectra of cadmium sulfide (CdS) and silica-coated quantum dots (QDs).

Note: The inset shows the ultraviolet illumination image of CdS QDs (left) and silica-coated CdS QDs (right).

of the silica-shielded CdS QDs and proves their increased photostability.

\section{Biocompatibility of QDs and silica-coated QDs}

To efficiently employ these nanomaterials as cellular imaging probes, imparting biocompatibility to them is of prime importance. Bare CdS QDs are reported to be toxic to cells, and their cytotoxicity becomes significant with increases in concentration. The cytotoxicity of bare QDs is due to the release of cadmium ions inside live cells, leading to ROS production and glutathione depletion. Our aim with silica coating was to minimize the toxicity, as the silica layer can efficiently block the release of cadmium ions from the $\mathrm{CdS}$ core. As described, cytotoxicity tests were carried out using alamarBlue. The cytotoxicity profiles of bare and silica-coated QDs were studied on HUVECs and Gl-1 cells. Upon the subsequent addition of the nanoparticles, cell viability decreased as a function of concentration and time. The densities of viable HUVECs observed under different concentrations after 24 hours incubation with the nanoparticles are presented in Figure 8. The cells showed an uptake of QDs within 2 hours and of silica-coated nanomaterial within 4 hours of incubation, as evidenced from confocal studies; hence, it was concluded that cytotoxic studies could be carried out after 24 hours. Bare QDs had comparatively higher levels of toxicity, even at the lowest concentrations $(1 \mu \mathrm{g})$, at which only $55 \%$ of cells were viable. At the highest concentration ( $1 \mathrm{mg}$ ), only $10 \%$ of the cells were viable. On the contrary, in the case of silica-coated QDs, the viability of the cells was greatly enhanced. The cell viability was as high as $60 \%$ at the highest concentration of $1 \mathrm{mg} / \mathrm{mL}$ of silicacoated QDs, highlighting the prominent biocompatibility acquired by these nanomaterials post-silica encapsulation. At concentrations of 10 and $1 \mu \mathrm{g} / \mathrm{mL}$, nearly $88 \%$ and $96 \%$ of cells were viable, respectively. In the case of Gl-1 cells, the cytotoxicity of bare QDs was highly pronounced, with only $3 \%$ of cells viable at the highest concentration $(1 \mathrm{mg} / \mathrm{mL})$. Even at a concentration of $1 \mu \mathrm{g} / \mathrm{mL}$, we could observe only around $40 \%$ viability. With silica-coated QDs, the viability

$$
\square 1000 \mu \mathrm{g} / \mathrm{mL} \quad=100 \mu \mathrm{g} / \mathrm{mL} \quad=10 \mu \mathrm{g} / \mathrm{mL} \quad \square 1 \mu \mathrm{g} / \mathrm{mL}
$$

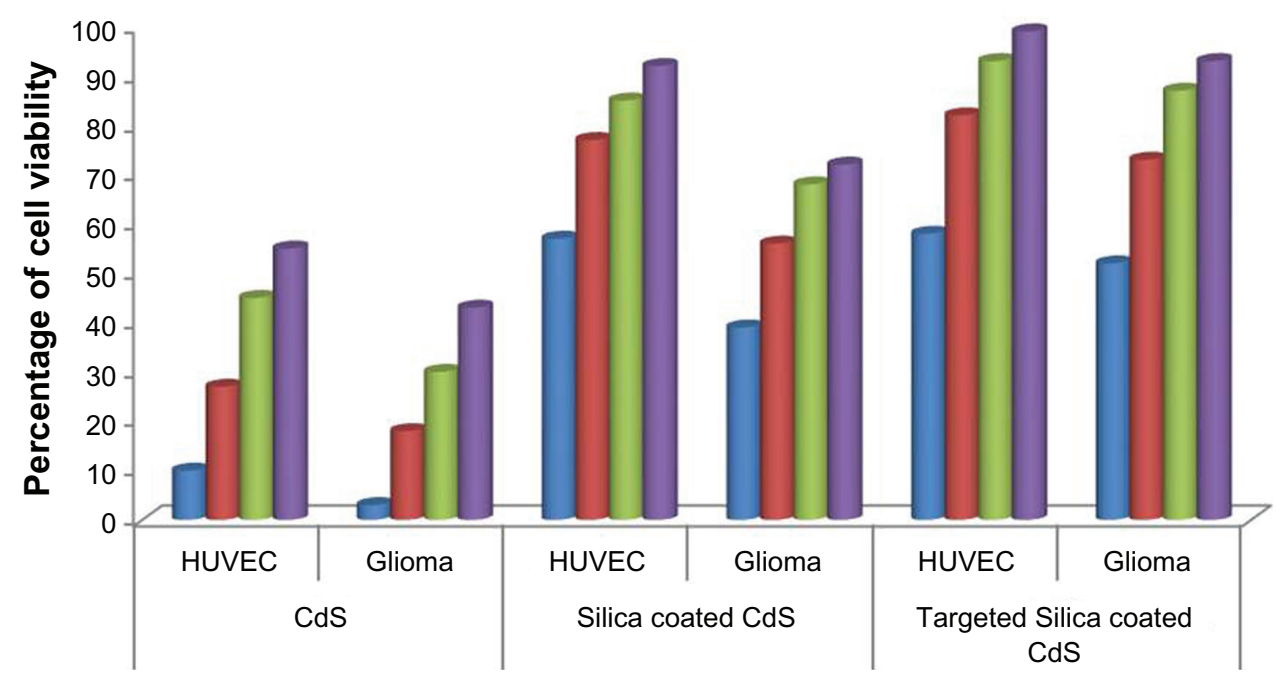

Figure 8 Effect of cadmium sulfide quantum dots (CdS QDs), silica-coated CdS QDs, and CD3I-targeted silica-coated CdS QDs on human umbilical vein endothelial cell (HUVEC) and glioma cell viability. 
was assessed to be around $75 \%$ and $40 \%$ at lower $(1 \mu \mathrm{g} / \mathrm{mL})$ and higher concentrations $(1 \mathrm{mg} / \mathrm{mL})$, respectively. Gl-1 cells are shown to effectively take up nanomaterials at higher levels than HUVECs, which was evidenced by confocal microscopic studies. The higher toxicity in G1-1 cells can be attributed to this increased uptake of nanomaterials within a short period. In the case of the targeted silica-coated CdS QDs, G1-1 cells showed less toxicity than those cells treated with non-targeted silica-coated CdS QDs. Meanwhile, in the case of HUVECs, viability remained the same as that of the non-targeted nanoparticle treatment. This might be due to the high specificity of antibody-labeled silica-coated QDs toward endothelial cells compared with Gl-1 cells, resulting in a decreased intake of nanomaterials in the latter. Alternatively, this may be attributed to the absence of CD31 markers on the surface of Gl-1 cell lines, corresponding directly to the significance of the high specificity of our targeted nanomaterial.

The cellular ROS formation, when subjected to nanoparticle (CdS and silica-coated CdS QDs) treatment, was also studied. As per the alamarBlue assay experiment, HUVECs and Gl-1 cells were treated with three concentrations of CdS and silica-coated CdS QDs. We were able to detect
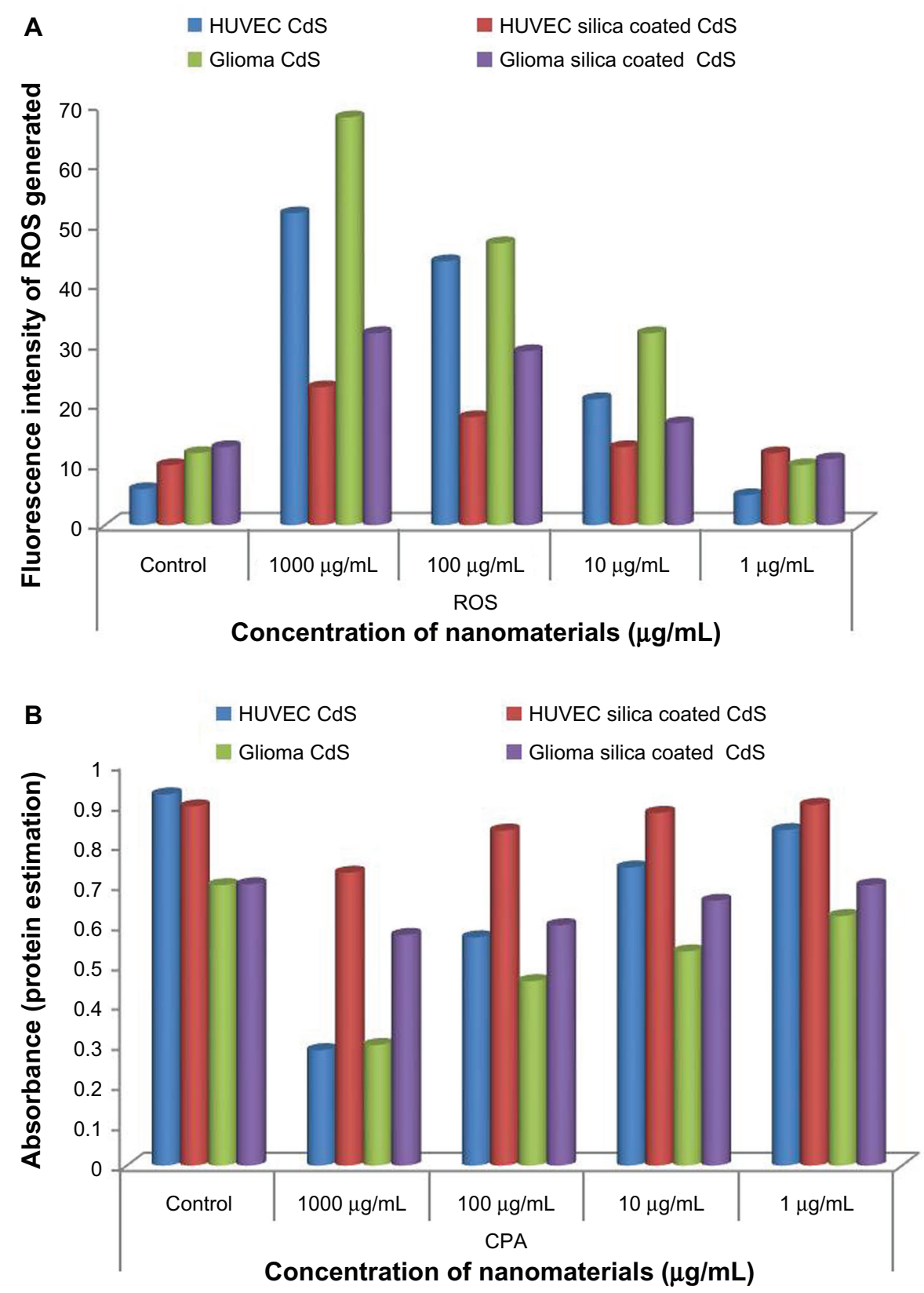

Figure 9 Effect of cadmium sulfide and silica-coated quantum dots on (A) cellular radical formation (reactive oxygen species [ROS]) and (B) on protein synthesis. Abbreviations: CPA, coomassie protein assay; HUVEC, human umbilical vein endothelial cell. 
higher levels of ROS formation in both cell lines treated with the CdS QDs than in the control group (Figure 9A). This ROS formation indicates released cadmium toxicity leading to cellular apoptosis. Coomassie protein assay showed that the total cellular protein production of both the cell lineages treated with CdS QDs was drastically reduced when compared with the control group (Figure 9B). This was attributed to the lower cellular metabolic activity of the cells treated with bare QDs. However, the ROS and protein production of silica-coated CdS QDs-treated cells remained comparable to the control group except at the concentration of $1 \mathrm{mg} / \mathrm{mL}$. At this concentration, the ROS production increased slightly. The protein production of cells treated with $1 \mathrm{mg} / \mathrm{mL}$ of silica-coated QDs showed slightly compromised metabolic activity. This insignificant increase in ROS and decreased protein production did not cause any lethal effects to the cells, reaffirming the biocompatibility attained with a silica coating.

In general, it was clearly evidenced that silica-coated QDs exert no significant cytotoxic effects on endothelial cells when compared with bare QDs, thereby suggesting they are highly safe labeling probes.

\section{Intake of nanomaterials by cells and imaging}

The cellular uptake and endocytosis of these nanomaterials were studied by means of a confocal microscope to determine the cellular uptake/entry of bare and silica-coated QDs. HUVECs and G1-1 cells were treated with as few as $100 \mu \mathrm{g} /$ $\mathrm{mL}$ of both nanomaterials and incubated for 1 hour (Figure 10). In the case of bare QDs, Gl-1 cells showed efficient uptake of nanomaterials after 1 hour of incubation. However, HUVECs were not efficiently labeled with bare QDs at 1 hour. This may be the reason for pronounced Gl-1 cell cytotoxicity, since they showed high uptake of nanomaterials within a short period. To check whether time-dependent uptake of bare QDs exists, we incubated both cell lines with bare QDs for 2 hours (Figure 11). After 2 hours, both cells showed efficient uptake of bare QDs and were effectively labeled. When the cells were incubated for a longer duration with bare QDs (24 hours), most of the Gl-1 cells died, rounded, and started to float (Figure 12); the HUVECs also started to undergo cell death. Shrinkage of HUVECs after 24 hours of incubation with bare QDs was observed.

Figure 13 shows the uptake and internalization of silica-coated QDs by HUVECs and Gl-1 cells after 2 hours of incubation with the nanomaterials. After 1 hour of incubation, no uptake of silica-coated nanomaterials was recorded by either the HUVECs or G1-1 cells. After 2 hours, both cell lines showed uptake of nanomaterials, but not as significantly as in case of bare QDs incubated for 2 hours. This may be because of the size effect of the nanomaterials under study. Bare QDs are 4-5 nm and are taken up efficiently after 2 hours of incubation, whereas

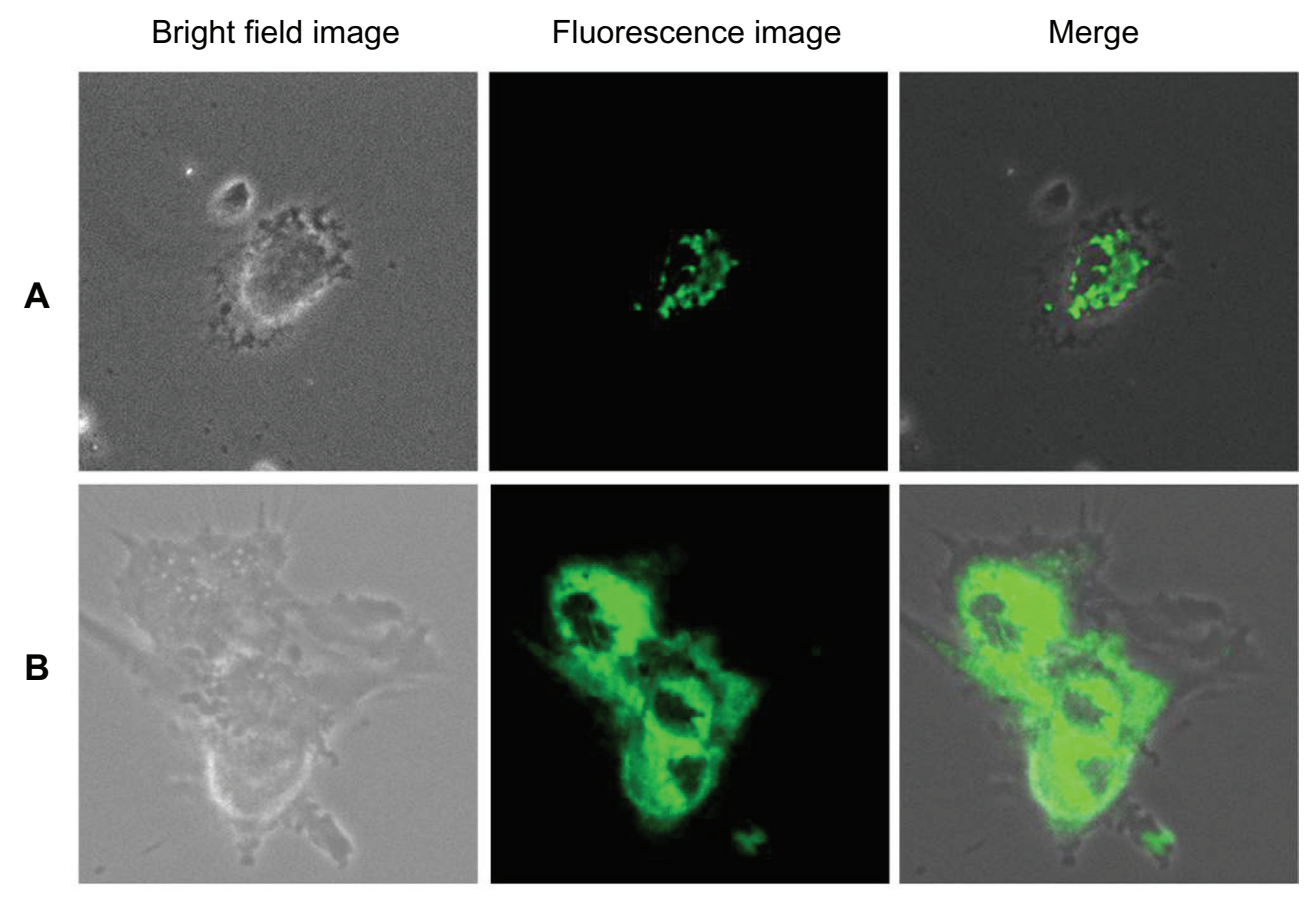

Figure 10 Imaging of (A) human umbilical vein endothelial cells and (B) glioma cells using cadmium sulfide quantum dots after I hour of incubation. 


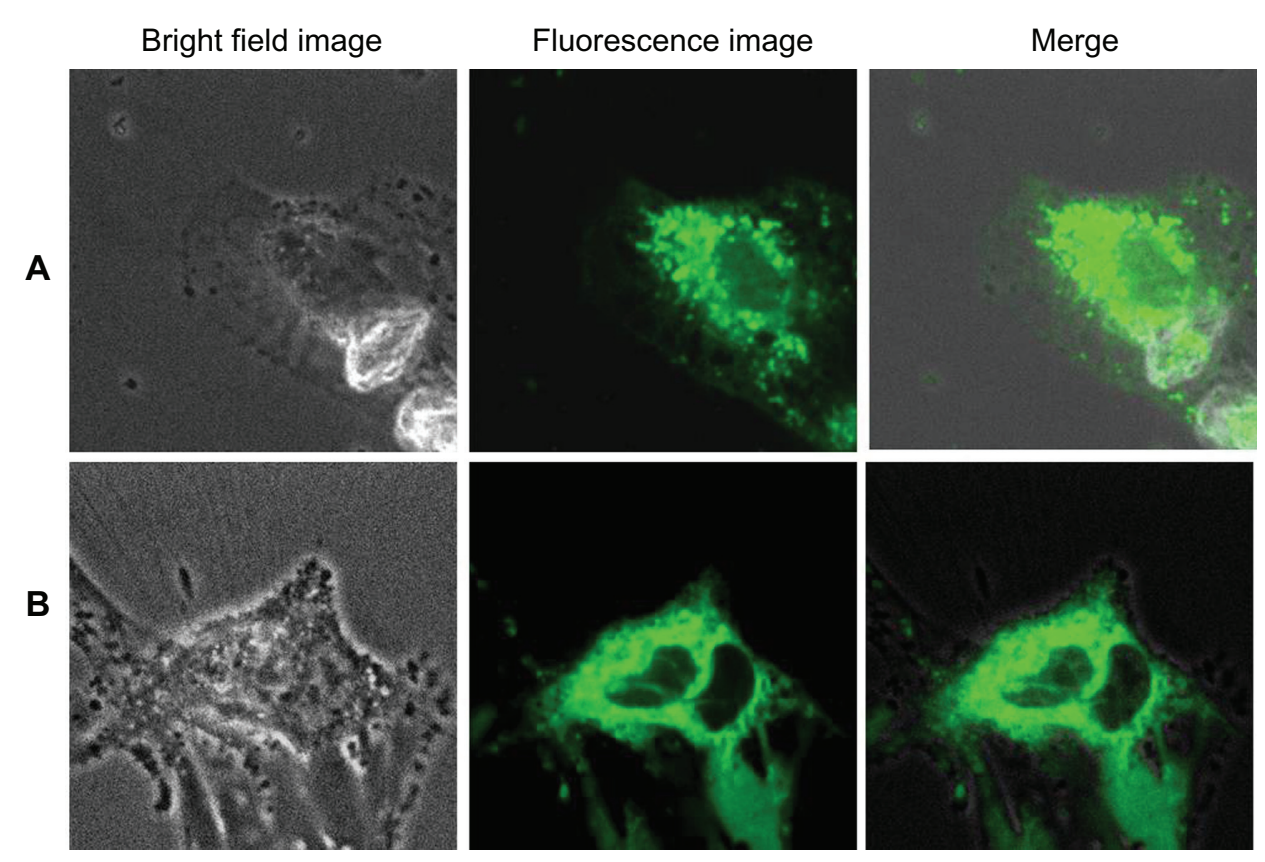

Figure I I Imaging of (A) human umbilical vein endothelial cells and (B) glioma cells using cadmium sulfide quantum dots after 2 hours of incubation.
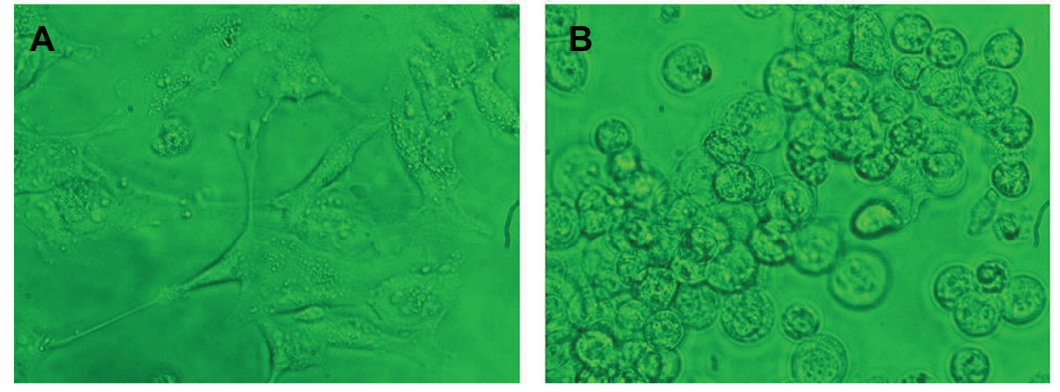

Figure 12 Human umbilical vein endothelial cells (HUVECs) (A) and glioma cells (B) after 24 hours of incubation with bare quantum dots. Note: The phase contrast images clearly show that HUVECs have started to undergo cell death, whereas the glioma cells are dead and rounded.

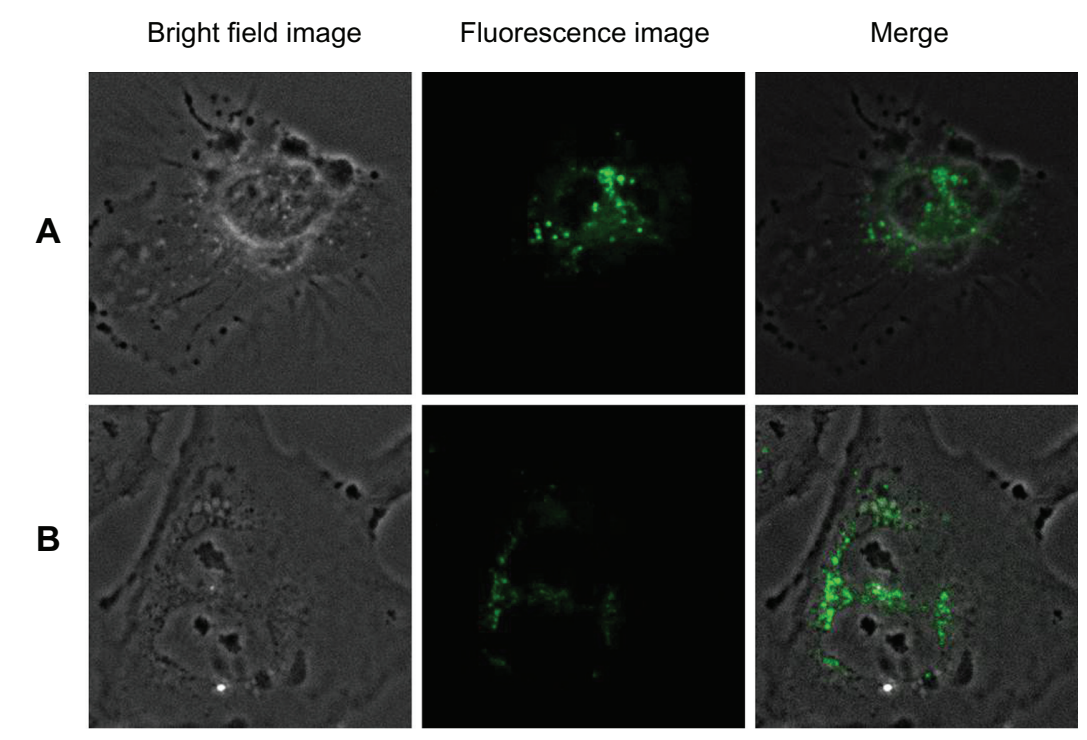

Figure 13 Imaging of (A) human umbilical vein endothelial cells and (B) glioma cells using silica-coated cadmium sulfide quantum dots after 2 hours of incubation. 


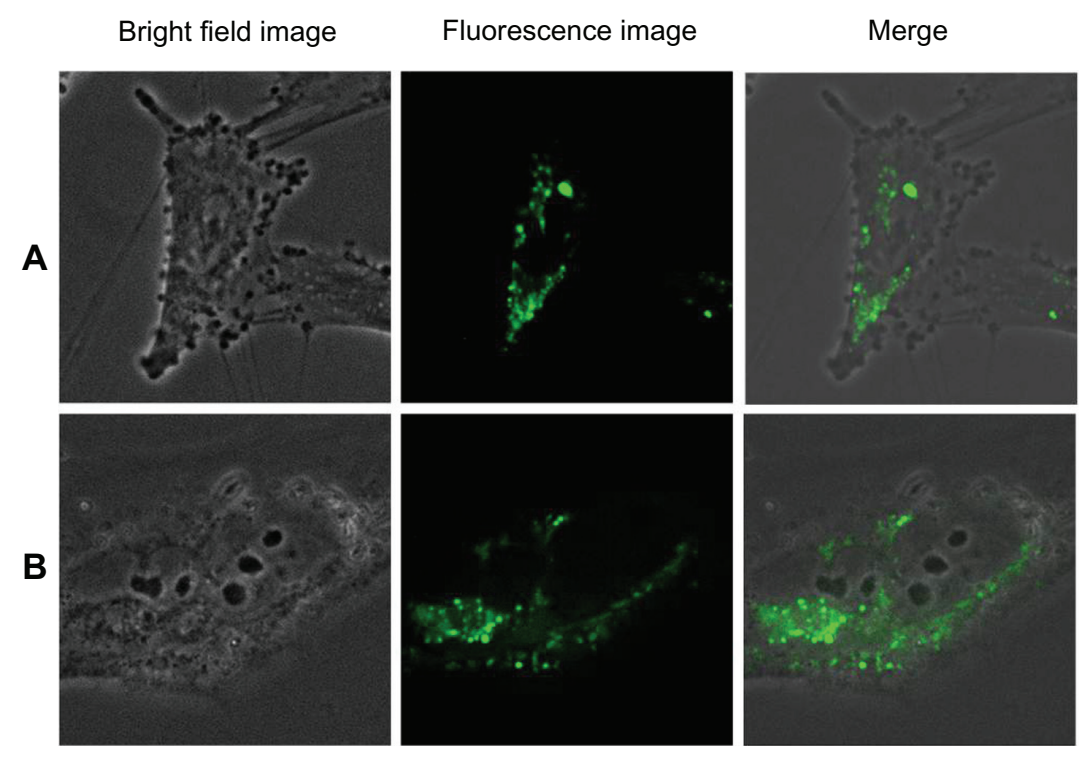

Figure 14 Imaging of (A) human umbilical vein endothelial cells and (B) glioma cells using silica-coated cadmium sulfide quantum dots after 4 hours of incubation.

silica-coated QDs are 35-40 nm, thereby presenting minimal intake in both cells. Apart from the size factor, this discrepancy in cellular uptake could also be due to the surface properties of the QDs and silica-coated QDs. When the cells were incubated with silica-coated QDs for 4 hours (Figure 14), comparable efficient uptake was observed. However, silica-coated QDs did not show rich fluorescence compared with bare QDs. Silica coating over QDs efficiently stabilized the fluorescent property of QDs, reducing their photobleaching, with limited reduction in fluorescence intensity. The cells treated with silica-coated QDs were viable even after 48 hours (data not shown), clearly indicating their biocompatibility. Thus, our results suggest that silica-coated QDs are effective cell labels due to their enhanced photostability for extended periods and their biocompatibility inside live cells.

Figure 15 shows the targeted imaging of endothelial cell lines by CD31-labeled silica-coated CdS QDs. G1-1 cells were used as a negative control, as they lack CD31 markers on their surfaces. Targeted nanoparticles were added to both cell
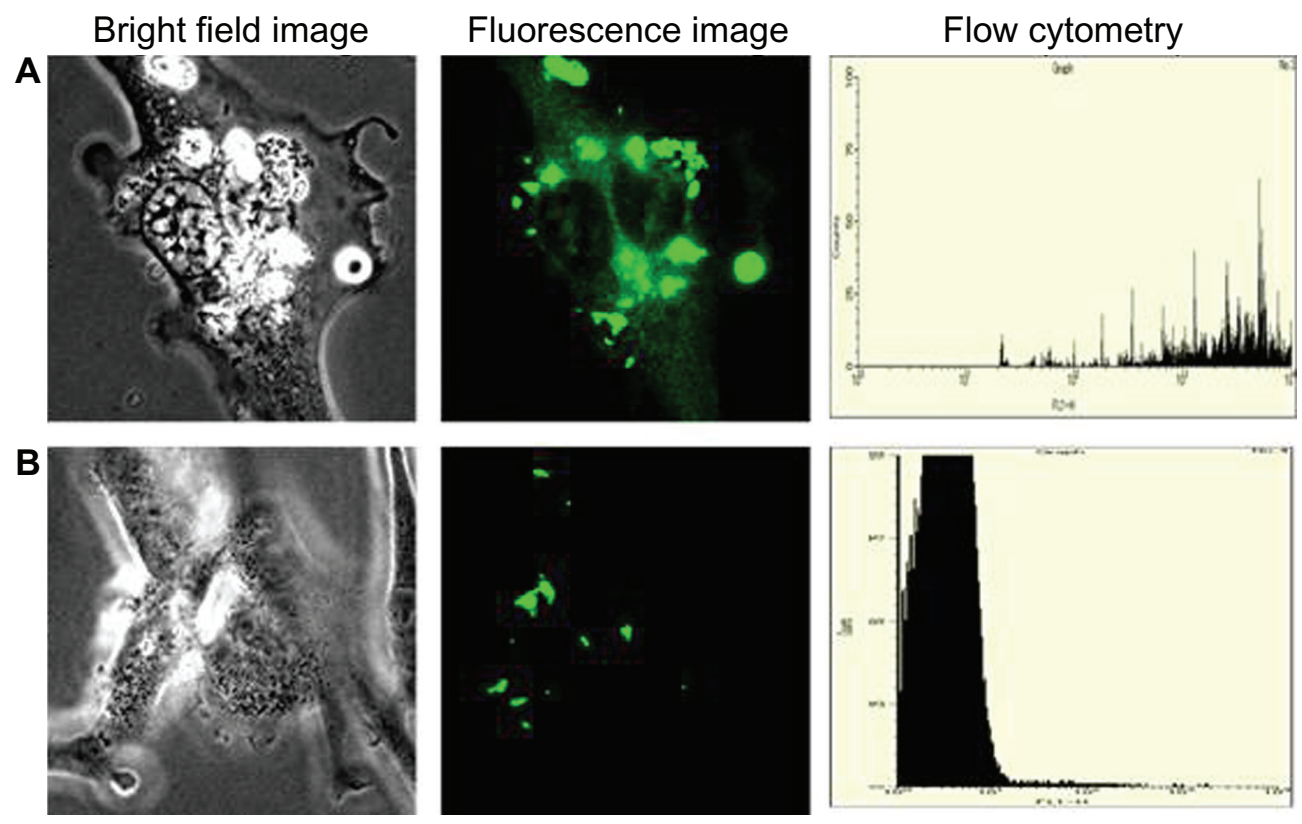

Figure 15 Imaging of (A) human umbilical vein endothelial cells and (B) glioma cells using CD3 I-labeled silica-coated cadmium sulfide quantum dots after I hour of incubation. 

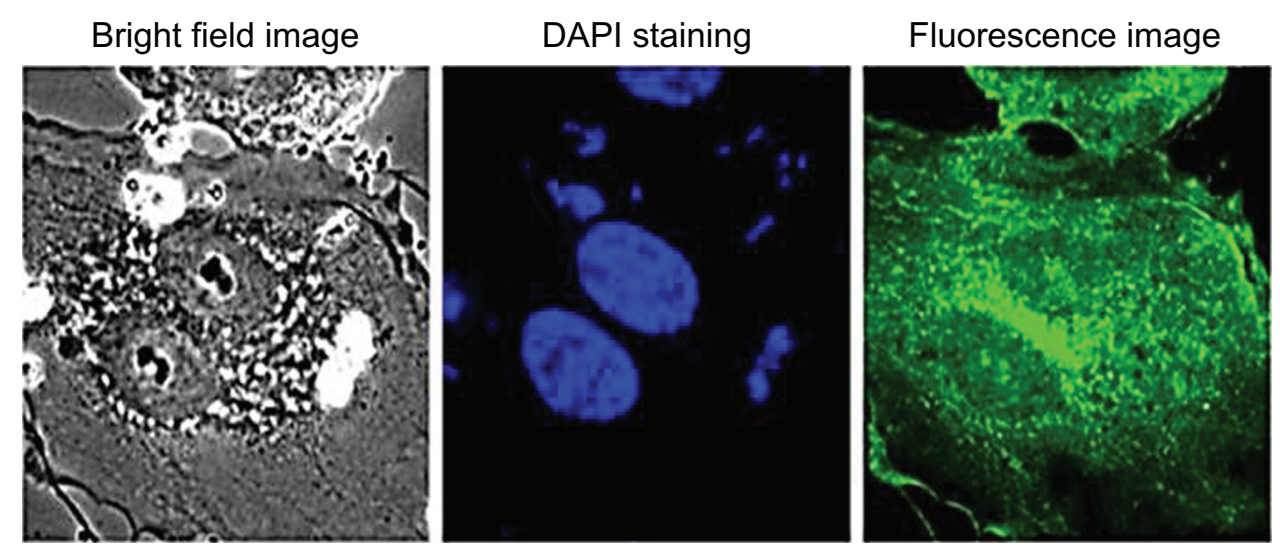

Figure 16 Viability staining and nuclear penetration of targeted silica-coated cadmium sulfide quantum dots.

lines and incubated. After 1 hour of incubation, the cells were washed to remove the unbound nanoparticles and were imaged using a confocal microscope. Highly efficient endothelial labeling was observed by the targeted nanoparticles. CD31 was expressed all over the surface of the cells. Further, the cytoplasm - including the nucleus - of the endothelial cells showed uptake of nanomaterials. Increased uptake was witnessed within 1 hour in the case of the endothelial cells, whereas the Gl-1 cells showed greatly decreased uptake of nanoparticles when compared with non-targeted treatment. Weak fluorescent signals from the nuclear region of HUVECs were observed after 1 hour of incubation. Therefore, the cells were incubated with targeted nanoparticles for 2 hours and a confocal microscopic study was carried out. Excellent uptake and internalization of targeted nanomaterials into the nuclear region was visualized, currently a first (Figure 16). Even though there was increased uptake of nanomaterials into the nuclear region, the 4',6-diamidino-2-phenylindole staining of the cells showed proper nuclear morphology. As mentioned previously, there was an increased uptake of non-targeted nanoparticles by Gl-1 cells when compared with HUVECs. However, with targeted nanoparticle treatment, Gl-1 cells showed weak and reduced fluorescent signals, suggesting the highly limited intake of targeted nanomaterial, in turn emphasizing the high specificity of the nanofactor toward HUVECs. Flow cytometry analysis was also carried out to determine the efficiency of targeted silica-coated CdS QDs with higher specificity toward HUVECs, sparing Gl-1s any internalization (Figure 15, right column). The flow cytometry data reveal that HUVECs showed nearly $10^{4}$ cells with particle internalization, whereas only $10^{1}$ Gl-1 cells showed internalization of nanoparticles. These results clearly indicate our success in achieving a breakthrough in high-specificity targeting of endothelial cells, which may carve a significant and prominent niche into in vivo vascular lineage imaging.

\section{In vivo applications}

To investigate the applicability and feasibility of bare and silica-coated QDs for in vivo imaging, we employed medaka embryos as test models. Embryos were exposed to both nanoparticles at a concentration of $100 \mu \mathrm{g} / \mathrm{mL}$ of ERM for 24 hours. After 24 hours, the embryos were viewed for the intrinsic biocompatibility of these two nanoparticles (Figure 17). We found that the embryos treated with CdS QDs had all shrunk, with blood clots evidently visible (Figure 17A). None of the embryos survived, proving the toxicity of cadmium-based QDs within 24 hours of incubation. This lethality of the CdS QDs can be attributed to the release of cadmium ions from the nanocrystals, which led to heavy metal toxicity, which correlates with the in vitro assay results. All embryos treated with silica-coated

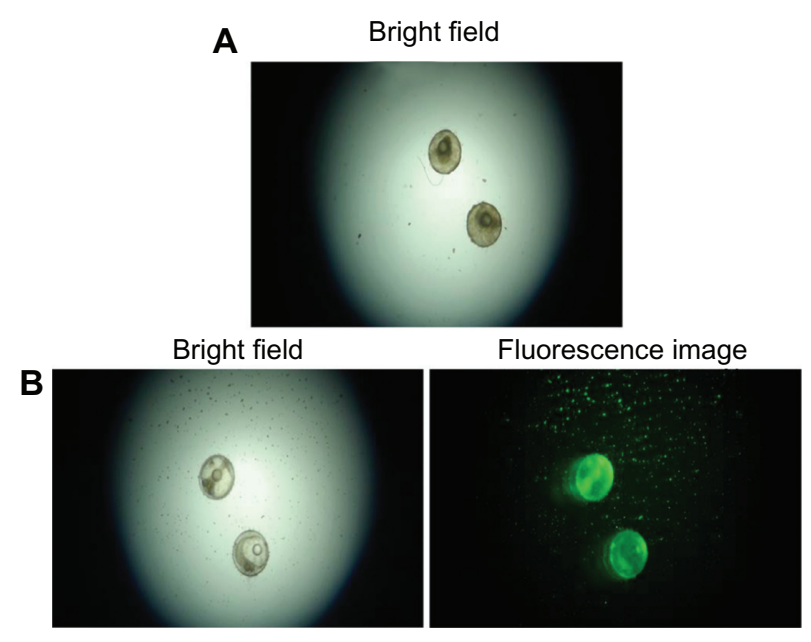

Figure 17 (A and $\mathbf{B}$ ) In vivo optical imaging of medaka embryos and a viability assessment using bare $\mathrm{CdS}$ and silica-coated cadmium sulfide quantum dots at a concentration of I $\mu \mathrm{g} / \mathrm{mL}$ of embryo-rearing medium. 

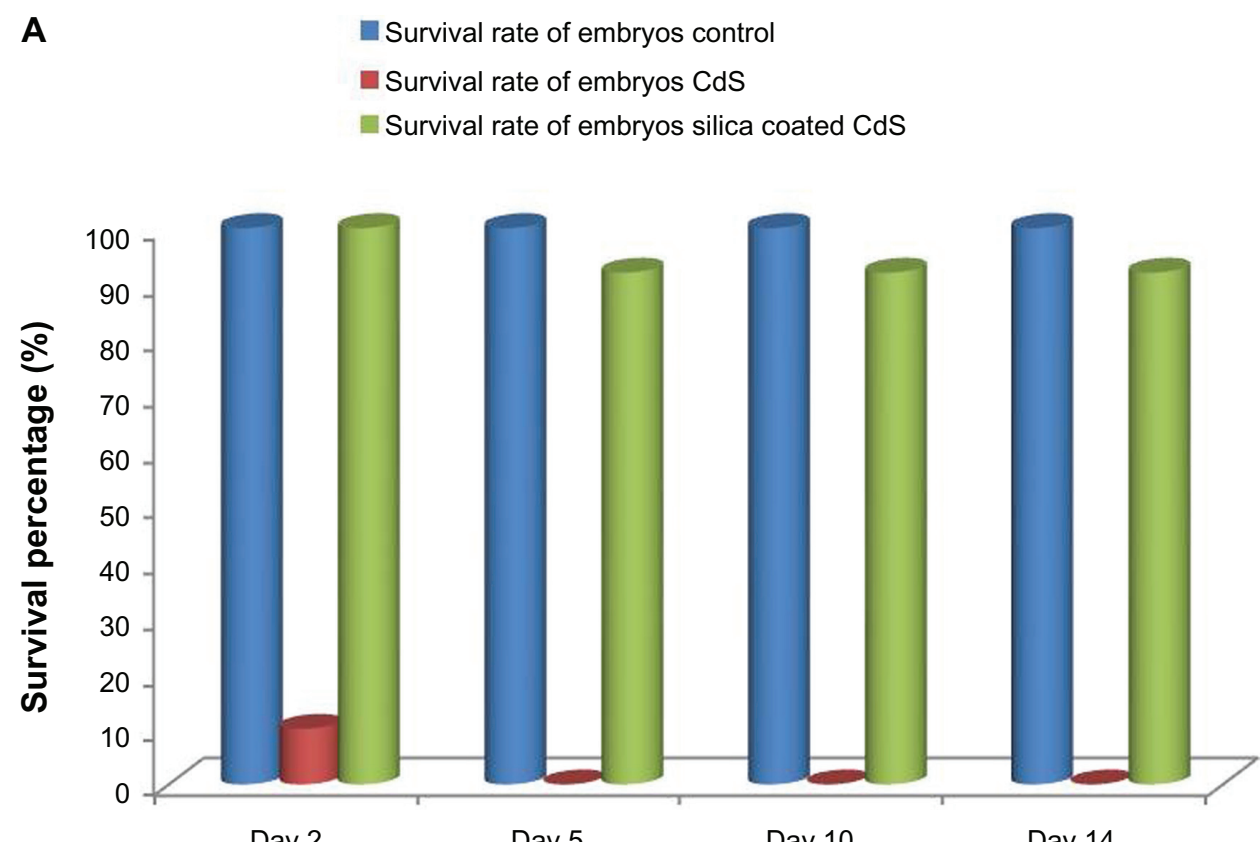

Nanoparticles exposure time

B Day 10 Day 11

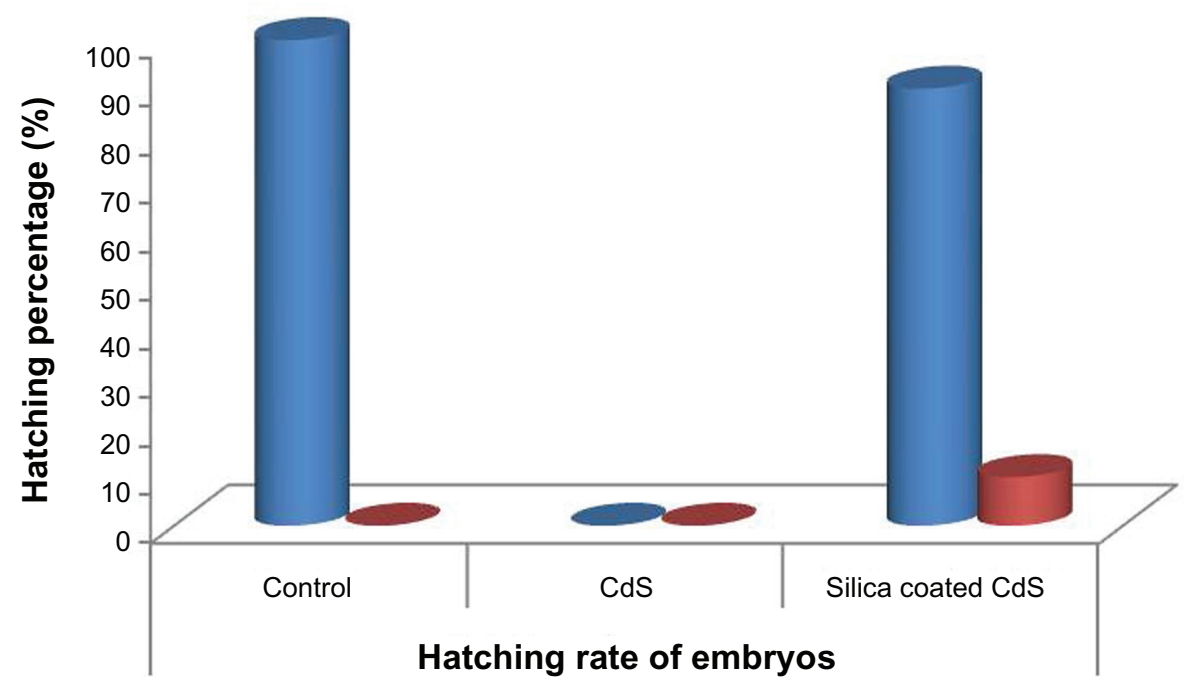

Figure 18 (A) Survival rate and (B) Hatching rate of embryos treated with bare cadmium sulfide (CdS) and silica-coated CdS quantum dots.

QDs were viable and healthy, without any notable deformities of the embryonic body, as with their control counterparts (Figure 17B). The survival and hatching rates of the embryos were examined to understand the toxic nature of QDs and the cytobio-amiability of silica-coated CdS QDs (Figure 18). In the case of CdS QDs, all test embryos were dead by Day 2 of nanoparticle exposure. However, with silica-coated QDs, the embryos remained viable and hatched concurrently with the control group, with the fry exhibiting a healthy profile. The heartbeats of the embryos treated with silica-coated QDs were also monitored (Supplementary video 1). This increased biocompatibility can be attributed to the presence of a silica shell, which prevents the leakage of cadmium ions from the QD core. The $20 \mathrm{~nm}$ silica shell around the core potentially plays a role in improvising biocompatibility. The silica-coated CdS QD-treated embryos were checked for particle uptake, which subsequently leads to fluorescence of the embryonic body of the medaka until hatching (Figures 17B and 19). This strong fluorescence of the silica-coated nanomaterials depicted the efficient uptake 


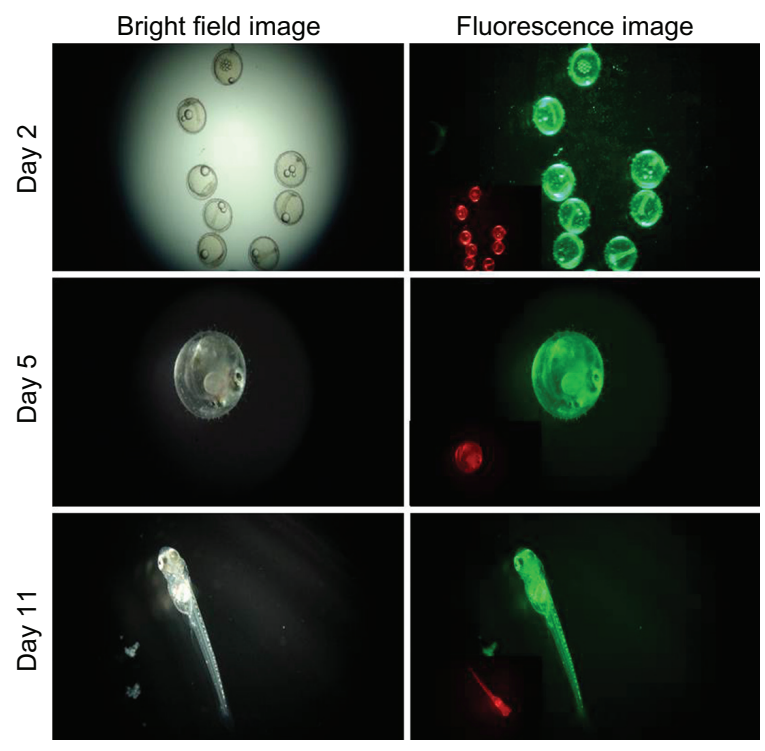

Figure 19 Fluorescence imaging of silica-coated cadmium sulfide quantum dottreated embryos.

Note: The inset in the fluorescence image shows the $56 \mathrm{I} \mathrm{nm}$ excitation under a red filter.

and internalization of silica-coated QDs into the embryonic body, clearly denoting the exceptional biocompatibility of the nanoparticles, along with their outstanding imaging ability.

Altogether, these silica-coated nanoparticles thus represent one of the new classes of nanocarriers for vascular theragnostics when targeted through specific ligands. This system holds promise for improving pharmacotherapy and easing antagonistic side effects when utilized for diagnostic therapy.

\section{Conclusion}

In this work, CdS and silica-coated CdS QDs were successfully synthesized. We demonstrated the uptake of CdS and silica-coated CdS nanomaterials in live cells. Successful employment of silica-coated CdS nanomaterials as efficient cell tags was achieved, and the prominent limitations of $\mathrm{CdS}$ QDs - such as toxicity and faster photobleaching - could be effectively countered. In addition to imparting biocompatibility and checking photobleaching, the silica coat also enhanced the shelf life of the QDs.

We report here the development of a QD-based targeting scheme to enhance selectivity, warranting higher specificity toward HUVEC cells. Thus, these fluorescent particles are proposed as highly proficient cell tags and can be directed for diagnostic targeting if suitably surface-functionalized. The fluorescence from the medaka embryos with any visible toxicity showed the potential of these silica-coated QDs in various biological labeling applications, including wholebody in vivo optical imaging involving tumor targeting and diagnosis. This study allows for the visualization of more accurate therapeutic delivery and diagnostic imaging applications in the near future based on highly adept tools such as QDs/silica nanomaterials.

\section{Acknowledgments}

Srivani Veeranarayanan, Aby Cheruvathoor Poulose, and M Sheikh Mohamed thank the Japanese Government's Ministry of Education, Culture, Sports, Science and Technology (MEXT) for providing financial support, as well as the Monbukagakusho fellowship. The authors thank Professor Fukushima for photoluminescence measurement assistance and Professor Katsuma for the XRD measurements.

\section{Disclosure}

The authors report no conflicts of interest in this work.

\section{References}

1. Brus LE. Electron-electron and electron-hole interactions in small semiconductor crystallites: the size dependence of the lowest excited electronic state. J Chem Phys. 1984;80(9):4403-4409.

2. Alivisatos AP. Perspectives on the physical chemistry of semiconductor nanocrystals. J Phys Chem. 1996;100(31):13226-13239.

3. Medintz IL, Uyeda HT, Goldman ER, Mattoussi H. Quantum dot bioconjugates for imaging, labelling and sensing. Nat Mater. 2005;4(6): 435-446.

4. Mansur HS. Quantum dots and nanocomposites. Wiley Interdiscip Rev Nanomed Nanobiotechnol. 2010;2(2):113-129.

5. Bruchez M Jr, Moronne M, Gin P, Weiss S, Alivisatos AP. Semiconductor nanocrystals as fluorescent biological labels. Science. 1998;281(5385): 2013-2016.

6. Chan WC, Nie S. Quantum dot bioconjugates for ultrasensitive nonisotopic detection. Science. 1998;281(5385):2016-2018.

7. Resch-Genger UR, Grabolle M, Cavaliere-Jaricot S, Nitschke R, Nann T. Quantum dots versus organic dyes as fluorescent labels. Nat Methods. 2008;5(9):763-775.

8. Shiohara A, Hanada S, Prabakar S, et al. Chemical reactions on surface molecules attached to silicon quantum dots. J Am Chem Soc. 2010;132(1):248-253.

9. Ballou B, Ernst LA, Andreko S, et al. Sentinel lymph node imaging using quantum dots in mouse tumor models. Bioconjug Chem. 2007; 18(2):389-396

10. Kuo CW, Chueh DY, Singh N, Chien FC, Chen P. Targeted nuclear delivery using peptide-coated quantum dots. Bioconjug Chem. 2011;22(6):1073-1080.

11. Yacobi NR, Phuleria HC, Demaio L, et al. Nanoparticle effects on rat alveolar epithelial cell monolayer barrier properties. Toxicol in Vitro. 2007;21(8):1373-1381.

12. Tang M, Xing T, Zeng J, et al. Unmodified CdSe quantum dots induce elevation of cytoplasmic calcium levels and impairment of functional properties of sodium channels in rat primary cultured hippocampal neurons. Environ Health Perspect. 2008;116(7):915-922.

13. Choi AO, Brown SE, Szyf M, Maysinger D. Quantum dot-induced epigenetic and genotoxic changes in human breast cancer cells. $J \mathrm{Mol}$ Med (Berl). 2008;86(3):291-302. 
14. Cho SJ, Maysinger D, Jain M, Röder B, Hackbarth S, Winnik FM. Long-term exposure to CdTe quantum dots causes functional impairments in live cells. Langmuir. 2007;23(4):1974-1980.

15. Mancini MC, Kairdolf BA, Smith AM, Nie SM. Oxidative quenching and degradation of polymer-encapsulated quantum dots: new insights into the long-term fate and toxicity of nanocrystals in vivo. $\mathrm{JAm} \mathrm{Chem}$ Soc. 2008;130(33):10836-10837.

16. Hoshino A, Fujioka K, Oku T, et al. Physicochemical properties and cellular toxicity of nanocrystal quantum dots depend on their surface modification. Nano Lett. 2004;4(11):2163-2169.

17. Mattoussi H, Mauro MJ, Goldman ER, et al. Self-assembly of CdSe-ZnS quantum dot bioconjugates using an engineered recombinant protein. J Am Chem Soc. 2000;122(49):12142-12150.

18. Salant A, Shalom M, Hod I, Faust A, Zaban A, Banin U. Quantum dot sensitized solar cells with improved efficiency prepared using electrophoretic deposition. ACS Nano. 2010;4(10):5962-5968.

19. Wang Y, Chen L. Quantum dots, lighting up the research and development of nanomedicine. Nanomedicine. 2011;7(4):385-402.

20. Lee J, Ji K, Kim J, et al. Acute toxicity of two CdSe/ZnSe quantum dots with different surface coating in Daphnia magna under various light conditions. Environ Toxicol. 2010;25(6):593-600.

21. Kim J, Park Y, Yoon TH, Yoon CS, Choi K. Phototoxicity of CdSe/ZnSe quantum dots with surface coatings of 3-mercaptopropionic acid or trin-octylphosphine oxide/gum arabic in Daphnia magna under environmentally relevant UV-B light. Aquat Toxicol. 2010;97(2):116-124.

22. Pinaud F, King D, Moore H, Weiss S. Bioactivation and cell targeting of semiconductor $\mathrm{CdSe} / \mathrm{ZnS}$ nanocrystals with phytochelatin-related peptides. J Am Chem Soc. 2004;126(19):6115-6123.

23. Hines MA, Guyot-Sionnest P. Synthesis and characterization of strongly luminescing ZnS-capped CdSe nanocrystals. J Phys Chem. 1996;100(2):468-471.

24. Wu X, Liu H, Liu J, et al. Immunofluorescent labeling of cancer marker Her2 and other cellular targets with semiconductor quantum dots. Nat Biotechnol. 2002;21(1):41-46.

25. Sperling RA, Parak WJ. Surface modification, functionalization and bioconjugation of colloidal inorganic nanoparticles. Philos Transact A Math Phys Eng Sci. 2010;368(1915):1333-1383.

26. Li JJ, Wang YA, Guo W, et al. Large-scale synthesis of nearly monodisperse $\mathrm{CdSe} / \mathrm{CdS}$ core/shell nanocrystals using air-stable reagents via successive ion layer adsorption and reaction. J Am Chem Soc. 2003;125(41): 12567-12575.

27. Hu X, Zrazhevskiy P, Gao X. Encapsulation of single quantum dots with mesoporous silica. Ann Biomed Eng. 2009;37(10):1960-1966.

28. Qian L, Bera D, Tseng TK, Hollaway PH. High efficiency photoluminescence from silica-coated CdSe quantum dots. Appl Phys Lett. 2009;94(7):073112-073114.

29. Tan TT, Selvan ST, Zhao L, Gao S, Ying JY. Size control, shape evolution, and silica coating of near-infrared-emitting PbSe quantum dots. Chem Mater. 2007;19(13):3112-3117.
30. Koole R, van Schooneveld MM, Hilhorst J, et al. Paramagnetic lipidcoated silica nanoparticles with a fluorescent quantum dot core: a new contrast agent platform for multimodality imaging. Bioconjug Chem. 2008;19(12):2471-2479.

31. Yi DK, Selvan ST, Lee SS, Papaefthymiou GC, Kundaliya D, Ying JY. Silica-coated nanocomposites of magnetic nanoparticles and quantum dots. J Am Chem Soc. 2005;127(14):4990-4991.

32. Selvan ST. Silica-coated quantum dots and magnetic nanoparticles for bioimaging applications. Biointerphases. 2010;5(3):FA110-FA115.

33. Selvan ST, Tan TT, Yi DK, Jana NR. Functional and multifunctional nanoparticles for bioimaging and biosensing. Langmuir. 2010;26(14):11631-11641.

34. Ruan J, Wang K, Song H, Xu X, Ji J, Cui D. Biocompatibility of hydrophilic silica-coated CdTe quantum dots and magnetic nanoparticles. Nanoscale Res Lett. 2011;6(1):299-312.

35. Gerion D, Pinaud F, Williams SC, et al. Synthesis and properties of biocompatible water-soluble silica-coated $\mathrm{CdSe} / \mathrm{ZnS}$ semiconductor quantum dots. J Phys Chem B. 2001;105(37):8861-8871.

36. Ma N, Marshall AF, Gambhir SS, Rao J. Facile synthesis, silanization, and biodistribution of biocompatible quantum dots. Small. 2010;6(14):1520-1528.

37. Veeranarayanan S, Cheruvathoor Poulose A, Mohamed S, et al. FITC labeled silica nanoparticles as efficient cell tags: uptake and photostability study in endothelial cells. J Fluoresc. 2012; 22(2):537-548.

38. Chan WC, Maxwell DJ, Gao X, Bailey RE, Han M, Nie S. Luminescent quantum dots for multiplexed biological detection and imaging. Curr Opin Biotechnol. 2002;13(1):40-46.

39. Wolcott A, Gerion D, Visconte M, et al. Silica-coated CdTe quantum dots functionalized with thiols for bioconjugation to $\mathrm{IgG}$ proteins. J Phys Chem B. 2006;110(11):5779-5789.

40. Nair R, Poulose AC, Nagaoka Y, Yoshida Y, Maekawa T, Kumar DS. Uptake of FITC labeled silica nanoparticles and quantum dots by rice seedlings: effects on seed germination and their potential as biolabels for plants. J Fluoresc. 2011;21(6):2057-2068.

41. Rempel SV, Kozhevnikova NS, Aleksandrova NN, Rempel AA. Fluorescent CdS nanoparticles for cell imaging. Inorganic Materials. 2011;47(3):223-226.

42. Chen Y, Rosenzweig Z. Luminescent CdS quantum dots as selective ion probes. Anal Chem. 2002;74(19):5132-5138.

43. Shuvaev VV, Ilies MA, Simone E, et al. Endothelial targeting of antibodydecorated polymeric filomicelles. ACS Nano. 2011;5(9):6991-6999.

44. Kashiwada S. Distribution of Nanoparticles in the See-through Medaka (Oryzias latipes). Environ Health Perspect. 2006;114(11): 1697-1702. 


\section{Supplementary information}

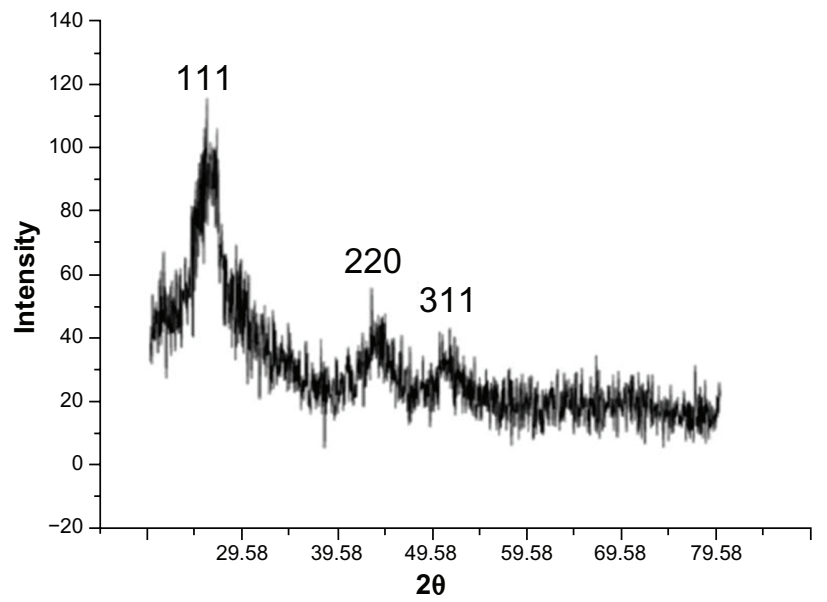

Figure SI X-ray diffraction pattern of bare cadmium sulfide quantum dots.
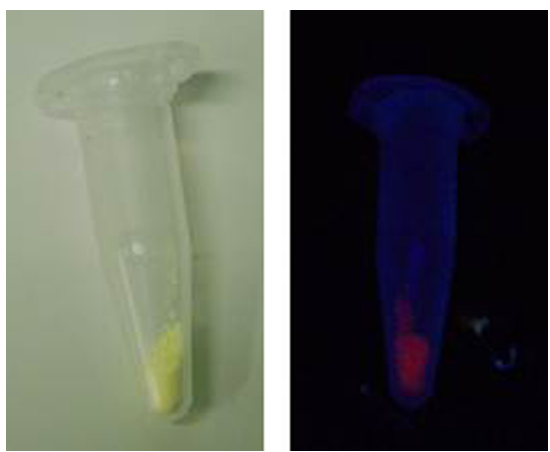

Figure S2 Ultraviolet (UV) luminescence image of silica-coated cadmium sulfide quantum dots after 3 months of normal day/night light storage to depict increased stable shelf life.

Notes: At right is the normal light image; at left is the UV illumination.

Supplementary video I Medaka embryos treated with silica-coated cadmium sulfide quantum dots (CdS QDs; A - Day 5 and C - Day I2). The viability of the embryos with their vital organs developed is shown. It is possible to visualize the heartbeat and blood pumping inside the cuverian duct. The video also depicts the biocompatibility of silica-coated CdS QDs. A video of the fluorescence for the same embryo is also provided (B - Day 5 and $\underline{D}-\underline{D}$ ay I2).

Supplementary video IA

Supplementary video IB

Supplementary video IC

Supplementary video ID

International Journal of Nanomedicine

Dovepress

\section{Publish your work in this journal}

The International Journal of Nanomedicine is an international, peerreviewed journal focusing on the application of nanotechnology in diagnostics, therapeutics, and drug delivery systems throughout the biomedical field. This journal is indexed on PubMed Central, MedLine, CAS, SciSearch $\AA$, Current Contents ${ }^{\circledR} /$ Clinical Medicine,
Journal Citation Reports/Science Edition, EMBase, Scopus and the Elsevier Bibliographic databases. The manuscript management system is completely online and includes a very quick and fair peer-review system, which is all easy to use. Visit http://www.dovepress.com/ testimonials.php to read real quotes from published authors. 